University of Wollongong

Research Online

Faculty of Social Sciences - Papers (Archive) Faculty of Arts, Social Sciences \& Humanities

2013

Neural time course of threat-related attentional bias and interference in panic and obsessive-compulsive disorders

Susan J. Thomas

University of Wollongong, sthomas@uow.edu.au

Craig J. Gonsalvez

University of Wollongong, craigg@uow.edu.au

Stuart J. Johnstone

University of Wollongong, sjohnsto@uow.edu.au

Follow this and additional works at: https://ro.uow.edu.au/sspapers

Part of the Education Commons, and the Social and Behavioral Sciences Commons

Research Online is the open access institutional repository for the University of Wollongong. For further information contact the UOW Library: research-pubs@uow.edu.au 


\title{
Neural time course of threat-related attentional bias and interference in panic and obsessive-compulsive disorders
}

\begin{abstract}
Attentional biases to threat are considered central to anxiety disorders, however physiological evidence of their nature and time course is lacking. Event-related potentials (ERPs) characterized sensory and cognitive changes while 20 outpatients with panic disorder (PD), 20 with obsessive-compulsive disorder (OCD), and 20 healthy controls (HCs) responded to the color (emotional Stroop task) or meaning of threatening and neutral stimuli. ERPs indicated larger P1 amplitude and longer N1 latency in OCD, and shorter P1 latency in PD, to threatening (versus neutral) stimuli, across instructions to attend to, or ignore, threat content. Emotional Stroop interference correlated with phobic anxiety and was significant in PD. Participants with emotional Stroop interference had augmented P1 and P3 amplitudes to threat (versus neutral) stimuli when color-naming. The results suggest early attentional biases to threat in both disorders, with disorder-specific characteristics. ERPs supported preferential early attentional capture and cognitive elaboration hypotheses of emotional Stroop interference.
\end{abstract}

\section{Keywords}

threat, course, time, neural, related, attentional, bias, disorders, compulsive, obsessive, panic, interference

\section{Disciplines}

Education | Social and Behavioral Sciences

\section{Publication Details}

Thomas, S. J., Gonsalvez, C. J. \& Johnstone, S. J. (2013). Neural time course of threat-related attentional bias and interference in panic and obsessive-compulsive disorders. Biological Psychology, 94 (1), 116-129. 


\section{Title page}

Neural time course of threat-related attentional bias and interference in panic and obsessivecompulsive disorders.

Running title: Time course of threat-related biases

Susan J. Thomas ${ }^{1,2}$ (corresponding author)

Craig J. Gonsalvez ${ }^{1,3}$

Stuart J. Johnstone ${ }^{1,3}$

1. Brain \& Behaviour Research Institute and School of Psychology, University of Wollongong, NSW, Australia.

2. Graduate School of Medicine, University of Wollongong, NSW Australia.

3. Centre for Psychophysics, Psychophysiology \& Psychopharmacology, University of Wollongong, NSW, Australia.

Correspondence address:

Graduate School of Medicine, University of Wollongong,

Northfields Avenue,

NSW, Australia, 2522.

Email: sthomas@uow.edu.au

Phone + 61242215928

Fax +61242214341 


\begin{abstract}
Attentional biases to threat are considered central to anxiety disorders, however physiological evidence of their nature and time course is lacking. Event-related potentials (ERPs) characterized sensory and cognitive changes while 20 outpatients with panic disorder (PD), 20 with obsessive-compulsive disorder (OCD), and 20 healthy controls (HCs) responded to the color (emotional Stroop task) or meaning of threatening and neutral stimuli. ERPs indicated larger P1 amplitude and longer N1 latency in OCD, and shorter P1 latency in PD, to threatening (versus neutral) stimuli, across instructions to attend to, or ignore, threat content. Emotional Stroop interference correlated with phobic anxiety and was significant in PD. Participants with emotional Stroop interference had augmented P1 and P3 amplitudes to threat (versus neutral) stimuli when color-naming. The results suggest early attentional biases to threat in both disorders, with disorder-specific characteristics. ERPs supported preferential early attentional capture and cognitive elaboration hypotheses of Emotional Stroop interference.
\end{abstract}




\section{Introduction}

The clinical presentation of anxiety disorders includes cognitive, affective, somatic and behavioral changes (APA, 2000; Zacharko, Koszycki, Mendella, \& Bradwejn, 1995). Cognitive alterations include a focus on thought content related to danger (Rachman, 2007; Tata, Leibowitz, Prunty, Cameron, \& Pickering, 1996), and sensitivity to threat-related cues in the environment (MacLeod, 2004). Attentional biases to threat appear to be causally related to clinical anxiety (MacLeod, 2004). They predict, for example, cortisol reactivity to stress, which may present a vulnerability to anxiety disorders (Fox, Cahill, \& Zougkou, 2010). Threat-related biases are therefore implicated as central to the etiology and maintenance of anxiety disorders (Williams, Mathews, \& MacLeod, 1996).

Over three decades, many studies have investigated threat-related biases in clinical and healthy populations, mostly relying on indirect measures such as reaction time (RT) impairment in secondary tasks when threat stimuli are present. RT studies have limitations in that they only allow for the study of biases accompanied by measurable behavioral changes, whereas attentional biases can occur independently of behavioral interference (e.g. van den Heuvel et al., 2005; Thomas, Johnstone, \& Gonsalvez, 2007). RT studies also provide little information about the relative involvement of sensory versus cognitive processes in threatrelated biases. The nature and timing of anomalies is of theoretical and clinical importance (Bar-Haim, Lamy, Pergamin, Bakermans-Kranenburg, \& van Ijzendoorn, 2007), as distinctions may guide treatments. Recently, neuroimaging studies have advanced our understanding of brain regions activated during threat processing in anxious and healthy participants, however neuroimaging studies also lack the temporal resolution to localize biases to specific information-processing stages. Additionally, RT and imaging studies indicate that brain and behavioral responses to phobic stimuli differ between obsessive- 
compulsive and other disorders (van den Heuvel et al., 2005), however these differences remain incompletely understood and controversial (Moritz et al., 2004).

\subsection{Imaging studies of threat processing}

A key laboratory method for investigating threat-related biases is the emotional Stroop task. In this task, slower RTs when naming ink-color of threat vs. neutral words are interpreted to indicate the presence of attentional biases, however usually no direct measure of attention is employed. Relatively recently, neuroimaging studies have shown that emotional Stroop tasks activate the affective ("rostral") subdivision of the anterior cingulate cortex (Bush, Luu, \& Posner, 2000; Whalen et al., 1998). In healthy individuals, reduced amygdala activity has been noted when color-naming threat words, which may indicate appropriate regulation of responses to irrelevant threats (Compton et al., 2003). Because behavioral interference is typically absent in healthy participants (Bishop, 2007; Whalen, et al., 1998), however, clinical comparisons are needed.

In an fMRI study of the emotional Stroop task (van den Heuvel, et al., 2005), PD participants were slower to color-name panic-related words, correlating with increased activation of the right amygdala. Participants with OCD were unimpaired when color-naming OCD related words, but showed increased bilateral amygdala activation relative to HCs, and increased right amygdala activation compared to patients with PD. These effects were interpreted to indicate attentional biases to disorder-specific stimuli in OCD and PD (van den Heuvel, et al., 2005). Additionally, OCD imaging studies show increased activation in orbitofrontal-subcortical, limbic and occipital regions during symptom provocation (Adler et al., 2000; Breiter \& Rauch, 1996; Chen, Xie, Han, Cui, \& Zhang, 2004; Nakao et al., 2005; Rauch, Savage, Alpert, Fischman, \& Jenike, 1997; van den Heuvel et al., 2004), indicating heightened neural responses to phobic stimuli. 
Despite improved understanding of the brain regions involved in emotional biases and emotional Stroop interference, imaging and RT studies have yet to clearly determine the time course and nature of information-processing mechanisms contributing to emotional Stroop interference. These could include facilitated sensory capture (Mogg, Bradley, De Bono, \& Painter, 1997), delayed disengagement (Fox, Russo, Bowles, \& Dutton, 2001), effortful avoidance or cognitive elaboration of threat stimuli (Bar-Haim, Lamy, Pergamin, BakermansKranenburg, \& van Ijzendoorn, 2007; Kyrios \& Iob, 1998). Alternatively, both early, automatic biases towards threat followed by avoidance of threatening stimuli during more strategic stages of processing (or vigilance-avoidance patterns) have been proposed (BarHaim, et al., 2007; Mogg, Bradley, De Bono, \& Painter, 1997; Williams, Watts, MacLeod, \& Mathews, 1997). Additionally, while all interpretations of emotional Stroop interference imply that primary processes (such as preferential processing or avoidance of threat) lead to secondary effects (delayed color naming), most studies offer no direct evidence of the primary processes. Emerging anxiety treatments are able to target early, automatic biases to threat (Cisler \& Koster, 2010) in addition to well established treatments such as cognitivebehavioral therapy which target more strategic processes. A greater understanding of the nature and timing of biases may help to refine treatments.

\subsection{ERP studies of threat processing in clinical anxiety}

Event-related potentials' (ERPs') exquisite temporal resolution and sensitivity to emotional processing provide a means to directly measure neural activity associated with threat processing and interference. ERP components occurring relatively early (e.g. the P1, N1 and P2 components) primarily reflect neural activity during sensory processing, whereas those occurring later (e.g. the N2, P3 components and late positive potentials or LPPs) reflect neural activity expended during higher-level cognition including inhibitory and memoryupdating processes (Duncan-Johnson \& Donchin, 1982; Kok, 2001; Picton, 1992). ERPs are 
sensitive to both the extent (amplitude) and speed (latency) of processing during sensory and cognitive stages, and can therefore potentially differentiate between hypotheses about the mechanisms underlying emotional Stroop interference. For example, P1 amplitude increases with attention to visual stimuli, with recruitment of extrastriate neurons to visual processing (Carretié et al., 2009; Hopfinger \& Mangun, 2001; Martinez et al., 1999; Smith, Cacioppo, Larsen, \& Chartrand, 2003), hence can provide a measure of the intensity and speed of sensory processing of threat versus neutral stimuli. Additionally, P3 amplitude is increased to meaningful or emotionally salient stimuli and is decreased to stimuli when participants are attending to another task, like reading a book (Kok, 2001). ERPs can therefore offer insight into primary processes involved in attention to threat and their relationship to secondary interference.

ERP research examining attention to phobic stimuli in clinical anxiety is currently scant. People with social phobia displayed enhanced right hemisphere N170, an ERP component linked to face processing, in the absence of behavioral effects, indicating anomalies in the early visual processing of angry faces (Kolassa \& Miltner, 2006). Additionally, individuals with spider phobias had larger parietal P300 amplitudes to spiders in a pictorial emotional Stroop task, indicating enhanced attention during central cognitive stages. In a visual dot probe task, socially phobic participants had potentiated P1 amplitudes to angry-neutral versus happy-neutral face-pairs and decreased P1 amplitudes to probes replacing emotional faces, taken to indicate hypervigilance-avoidance patterns of attention (Mueller et al., 2009). While these studies have provided additional information about attentional biases to threat in anxiety, pictorial stimuli do not reliably induce RT interference (Kindt \& Brosschot, 1999; Kolassa \& Miltner, 2006; Kolassa, Musial, Mohr, Trippe, \& Miltner, 2005; Lavy, van den Hout, \& Arntz, 1993; Mueller et al., 2009), hence these studies have not determined the mechanisms mediating emotional Stroop interference. 
There is evidence that emotional content influences ERPs to words during early time windows such as the P1 time window (80-120 ms; Bayer, Sommer, \& Schacht, 2012; Bernat, Bunce, \& Shevrin, 2001; Junghöfer, Bradley, Elbert, \& Lang, 2001; Li, Zinbarg, \& Paller, 2007; Scott, O'Donnell, Leuthold, \& Sereno, 2009), and that involuntary attention allocation in the visual cortex is not limited to pictorial stimuli, but can occur for word stimuli which have only arbitrary relationships between their visual features and corresponding meaning (Bayer, et al., 2012; Ortigue et al., 2004; Rabovsky, Sommer, \& Abdel Rahman, 2011). While such effects occur earlier than serial models of language processing would predict, there are proposals that word emotional valence detection may precede and facilitate lexical access (Conrad, Recio, \& Jacobs, 2011) and that semantic features can influence sensory processing in the extrastriate cortex (Rabovsky, et al., 2011). Alternatively, nonlinguistic mechanisms may contribute to early emotion effects, such as feature detection or associative learning processes that do not depend on lexical access (Bayer, et al., 2012).

Only one study has examined ERPs associated with color-naming emotional words in clinical anxiety (post traumatic stress disorder; Metzger, Orr, Lasko, McNally, \& Pittman, 1997). While ERPs did not reveal the source of emotional Stroop interference, only the P3 component was analyzed, leaving the possibility that earlier or later effects were overlooked. The small sample size $(n=9)$ may also have limited the power to detect differences.

\subsection{ERPs during traditional Stroop tasks}

Numerous ERP studies have examined interference effects in traditional (nonemotional) Stroop tasks. These involve enhanced fronto-central or broad negativity 350-500 ms possibly indexing conflict (Liotti, Woldorff, PerezIII, \& Mayberg, 2000), and a sustained negativity over lateral frontal areas and greater positivity centro-parietally, possibly reflecting additional processing of word meaning (Liotti, et al., 2000; West, 2003). Emotional and traditional Stroop tasks, however, differ on important dimensions. Only traditional Stroop 
tasks evoke direct conflict between stimulus dimensions (e.g. the word red appearing in blue font), and neural changes during emotional Stroop tasks are likely indexing emotional salience and interference rather than conflict (Algom, Chajut, \& Lev, 2004), necessitating separate investigations.

\subsection{Non-clinical ERP studies of emotional Stroop tasks}

Several ERP studies have examined emotional Stroop phenomena in non-clinical samples. Sensory effects vary, with some studies finding no effect of emotion on P1 (PérezEdgar \& Fox, 2003; Thomas, Johnstone, \& Gonsalvez, 2007), and one finding P1 amplitude enhancement with trait anxiety (Li, Zinbarg, \& Paller, 2007). Studies finding effects of emotion on P1 amplitude independent of anxiety both used blocked, predictable stimuli (Sass et al., 2010; van Hooff, Dietz, Sharma, \& Bowman, 2008), interpreted as likely reflecting top-down augmentation of early attention (van Hooff, et al., 2008), rather than attentional biases. No consistent patterns emerged for N1, P2 or N2. Many studies found higher P3, LPPs (Li, et al., 2007; Sass, et al., 2010; Taake, Jaspers-Fayer, \& Liotti, 2009; Thomas, et al., 2007), to negative versus netural stimuli.

Generally these non-clinical studies did not find RT interference (Fisher et al., 2010; Li, et al., 2007; Sass, et al., 2010; Taake, et al., 2009; Thomas, et al., 2007), although it was induced in limited conditions in two studies (Taake, et al., 2009; van Hooff, et al., 2008). Only two RT interference- ERP relationships were reported. One study found broadly distributed greater negativity 500-600 ms during interference trials, believed to reflect suppression of meaning representations (van Hooff, et al., 2008). Another reported increased fronto-central negativity across stimuli during threat/ neutral blocks than positive/ neutral blocks, 350-400 ms over fronto-central scalp, in a high anxiety sensitivity group, interpreted to indicate suppression of competing responses (Taake, et al., 2009). Participants with anxiety disorders typically exhibit robust interference (Williams, et al., 1996), and therefore futher 
studies are justified, to examine whether qualitaitve information-processing differences occur in clinical disorders.

\subsection{ERP studies of emotion in non-clinical participants}

ERP studies more broadly report larger LPPs to negative versus neutral stimuli in non-clinical samples, interpreted as an adaptive prioritization of attention to salient stimuli, or an affective "negativity bias" (Baumeister, Bratslavsky, Finkenauer, \& Vohs, 2001; Carretié, Mercado, Tapia, \& Hinojosa, 2001). Modulations of earlier (P1-N2) ERP components vary according to methodologies (Kissler, Herbert, Winkler, \& Junghofer, 2009; van Hooff, et al., 2008) and trait anxiety (Taake, et al., 2009). In non-anxious participants there is no consistent effect of emotion on P1 (Frühholz, Jellinghaus, \& Herrmann, 2011; Junghöfer, et al., 2001; Keil et al., 2002; Kissler, et al., 2009) or on ERP latencies (Brown, El-Deredy, \& Blanchette, 2010; Olofsson, Nordin, Sequeira, \& Polich, 2008; 2007). Many studies find altered electrophysiological activity to threat (versus neutral) stimuli in the absence of detectable behavioral differences, indicating the sensitivity of ERPs (Bar-Haim, Lamy, \& Glickman, 2005; Brown, et al., 2010; Thomas, et al., 2007; Weinstein, 1995) and dissociation between attentional and behavioral effects.

\subsection{ERPs in patients with PD}

We identified only three ERP studies of PD which included emotional stimuli, all examining memory. One study found larger P300 amplitudes to panic stimuli in PD interpreted as enhanced affective perception and processing of panic related words (Pauli et al., 1997). Another found enhanced positivity 200-400 ms to panic words along with reduced frontal ERP differentiation between negative and neutral words between $300-500 \mathrm{~ms}$ in PD, interpreted as dysfunctional inhibitory modulation of affective information processing in panic disorder (Windmann, Sakhavat, \& Kutas, 2002). A third reported undifferentiated ERPs between groups (Pauli, Dengler, \& Wiedemann, 2005). Because evidence is stronger 
for attentional than for memory biases in anxiety disorders (Dalgleish \& Watts, 1990), it is germane to investigate ERPs in PD during tasks such as the emotional Stroop which cause reliable behavioral interference (Lundh, Wikstrom, Westerlund, \& Ost, 1999; McNally et al., 1994; McNally, Kaspi, Riemann, \& Zeitlin, 1990), however we identified no such studies.

\subsection{ERPs in OCD}

The sensitivity of ERPs to attentional biases (Bar-Haim, et al., 2005; Thomas, et al., 2007) may also help to resolve controversy regarding attentional biases to threat in OCD. While some RT studies of OCD indicate delayed color-naming of threat words (Foa, Ilai, McCarthy, Shoyer, \& Murdock, 1993; Lavy, Van Oppen, \& Van Den Hout, 1994; Moritz et al., 2009), many report null findings (Kampman, Keijsers, Verbraak, Naring, \& Hoogduin, 2002; Kyrios \& Iob, 1998; McNally, Riemann, \& Kim, 1990; Moritz et al., 2008; Moritz et al., 2004). Studies using alternative experimental approaches to investigate attentional biases in OCD have also yielded equivocal results (Moritz \& von Mühlenen, 2008; Moritz, Von Muhlenen, Randjbar, Fricke, \& Jelinek, 2009; Tata, et al., 1996). This could be due to failure to tailor experimental stimuli to idiosyncratic OCD concerns (Muller \& Roberts, 2005). Alternatively, OCD may differ from other anxiety disorders, in being characterized less by phobic biases than by content-independent, neuropsychological, deficits which are distinct from other anxiety disorders (Kuelz, Hohagen, \& Voderholzer, 2004; Moritz, et al., 2004; Saxena \& Rauch, 2000; Summerfeldt \& Endler, 1998). A third possibility is that attentional biases are present in OCD, however they differ from PD in the extent to which they are associated with behavioral interference (van den Heuvel, et al., 2005). There are proposals for example, supported by neuroimaging data, that OCD may involve compensatory effortful control strategies for selective inhibition which allow normal behavioral performance despite intrinsic/extrinsic interference (Ciesielski, Hamalainen, Lesnik, Geller, \& Ahlfors, 2005).

Existing OCD ERP research focuses almost exclusively on attention to neutral 
stimuli. While ERP differences between OCD and HCs are consistently reported, specific findings vary, and OCD-specific deficits have yet to be identified. In oddball tasks, differences in OCD relative to HCs include both larger (Miyata et al., 1998; Towey et al., 1990; Towey et al., 1993) and smaller N2 amplitudes (Morault, Bourgeois, Laville, Bensch, \& Paty, 1997), interpreted as a misallocation of cognitive resources in OCD (Towey, et al., 1993). Increased N1 latency has been reported, interpreted to indicate possible impairments in evaluating the significance of the stimuli (Di Russo, Zaccara, Ragazzoni, \& Pallanti, 2000; Morault, et al., 1997). Additionally, reduced P3 latencies (Kivircik, Yener, Alptekin, \& Aydin, 2003; Morault, et al., 1997; Sanz, Molina, Martin-Loeches, Calcedo, \& Rubia, 2001; Towey, et al., 1990; Towey, et al., 1993) in OCD have been interpreted as a sign of cortical hyperarousal and overfocused attention (Towey, et al., 1993). Both larger (Gohle et al., 2008), and smaller P3 amplitude (Oades, Dittmann-Balcar, Schepker, Eggers, \& Zerbin, 1996) has been reported. Go/NoGo studies of inhibitory processes report reduced frontal NoGo despite normal performance (Herrmann, Jacob, Unterecker, \& Fallgatter, 2003; Malloy, Rasmussen, Braden, \& Haier, 1989), larger relative N1 and P3 Go activation (Di Russo, et al., 2000), and increased NoGo N2 amplitude (Ruchsow et al., 2007) in OCD compared to controls. Inconsistencies may be due to the differing stimulus complexity and task difficulty between studies, and overall the results indicate some general anomalies in sensory and cognitive attentional allocation relative to healthy controls.

Apparently only one previous study has examined ERPs to emotional stimuli in OCD (Johannes et al., 1999). Patients with OCD and co-morbid Tourette's Syndrome (TS) showed a diminished old/new effect to negative words $350-550 \mathrm{~ms}$ post-stimulus, possibly indicating changed memory for emotional words in OCD or TS. Given the clinical focus in OCD on affect-laden material, and the sensitivity of ERPs to attentional biases (Bar-Haim, et al., 2005; Thomas, et al., 2007), the lack of studies is surprising. Individuals with OCD do not 
complain of global inhibitory deficits (Moritz, Kloss, von Eckstaedt, \& Jelinek, 2009), but experience difficulty inhibiting thoughts which are personally repugnant, hence the need to investigate attention to affective stimuli. Another shortcoming of the OCD literature is that, as with brain imaging studies (Radua, van den Heuvel, Surguladze, \& Mataix-Cols, 2010; Rauch, et al., 1997; van den Heuvel, et al., 2005), ERP studies comparing OCD with other disorders are extremely rare (Miyata, et al., 1998; Oades, Zerbin, Dittmann-Balcar, \& Eggers, 1996; Schall et al., 1997), limiting conclusions about OCD-specific deficits.

In summary of the ERP data on emotional processing, early sensory preferential attention to threat stimuli does not generally occur in non-clinical participants but has been observed with highly anxious non-clinical participants and in blocked designs maximising top-down expectation. In contrast, amplitude of LPPs frequently varies as a function of threat content in healthy participants and therefore may reflect adaptive attention to salient environmental stimuli. Studies have yet to examine the involvement of sensory versus cognitive processing in emotional word Stroop effects in clinical anxiety and there is a dearth of ERP research examining attention to threat stimuli in PD or OCD.

\subsection{The current study}

The current study addressed the following unanswered questions: Firstly, do ERPs provide evidence of attentional biases to threat in both PD and OCD, and if so do these vary across disorders? We predicted early attentional biases in the form of larger or faster sensory (P1/N1) ERPs to threat versus neutral words in both clinical groups, and hypothesized that neural activity accompanying threat processing would differ between OCD and PD based on imaging studies indicating disorder-specific patterns of heightened amygdala activity to phobic stimuli in both PD and OCD (e.g. van den Heuvel, et al., 2005). We predicted RT interference to color name threat words in the PD but not OCD groups, because most 
previous RT studies report null effects in OCD (Kampman, et al., 2002; Kyrios \& Iob, 1998; McNally, Riemann, et al., 1990; Moritz, et al., 2008; Moritz, et al., 2004).

Secondly, what neural changes underlie emotional Stroop RT effects, and do these involve early sensory or later cognitive stages of information processing, or both?

If emotional Stroop interference arises through preferential sensory processing of threat words, this would be supported by significantly shorter latencies and/ or higher amplitude of $\mathrm{P} 1, \mathrm{~N} 1$ or $\mathrm{P} 2$ components in participants exhibiting RT interference to threat words. If emotional Stroop interference arises through inhibitory deficits or cognitive elaboration of threat stimuli, anomalies should be observed to threat stimuli in the N2 or P3 components in participants demonstrating interference. Larger P3 amplitude to threat versus neutral words in participants with interference would support cognitive elaboration of threat stimuli, whereas the opposite pattern would be consistent with cognitive avoidance.

ERPs were used as measures of attention to threat and neutral stimuli in PD, OCD and HCs, using an approach established earlier with a separate healthy sample (Thomas, et al., 2007). To distinguish between attentional capture versus effortful avoidance explanations of emotional Stroop interference, we presented identical stimuli across two tasks with requirements to classify them according to their color or threat value. We reasoned that effortful avoidance of threat stimuli would be at least as great when anxious participants were directed to read and classify words according to their threat value as when they were required to ignore the meaning and attend to the color of stimuli. Therefore to support the effortful avoidance hypothesis, delayed RTs should occur to threat words across tasks. Alternatively, RT delays when color-naming threat words, along with faster RTs to respond to threat words when they are task-relevant, would suggest that emotional Stroop interference arises due to preferential processing of threat stimuli which impairs performance in the concurrent task. 
Because threat appraisal, particularly in OCD, is idiosyncratic (Muller \& Roberts, 2005), the threat value of stimuli was determined separately for each participant.

\section{Materials and methods}

\subsection{Participants}

Sixty individuals participated: 20 with OCD, 20 with PD with or without agoraphobia, and $20 \mathrm{HCs}$. Clinical participants were recruited through local outpatient psychiatry and psychology clinics. They were first screened by telephone to ensure primary existing diagnosis of either PD or OCD. While some patients were prescribed benzodiazepines for occasional use, none had taken benzodiazepines in the preceding 48 hours. HCs were free from past and present psychiatric disorders. Exclusion criteria across groups were head injuries, neurological or substance disorders and psychoses. The University of Wollongong Ethics Committee approved the research protocol and participants gave written informed consent.

\subsection{Symptom measurement}

Diagnoses were confirmed using the Composite Interview for DSM-IV (World Health Organization, 1997). Participants completed the Brief Symptom Inventory (BSI), a measure of psychological distress (Derogatis \& Melisaratos, 1983), and the Padua Inventory Washing State University Revision, a measure of obsessive-compulsive symptoms (Burns, Keortge, Formea, \& Sternberger, 1996). Participants with OCD also completed the Yale-Brown Obsessive-compulsive Scale (Y-BOCS) which measures OCD severity (Goodman et al., 1989).

\subsection{Stimuli}

A pool of threat words was compiled from previous emotional Stroop studies (see Thomas, et al., 2007), including general, OCD-related and panic threat words. Neutral words were matched for length and frequency of usage. Individual ratings were obtained from 
participants as to the threat value of the words by asking them to indicate "How disturbing is this word to you (including associations with unpleasant thoughts, feelings or anxiety)?" on a five point Likert type scale ranging from 0 (not at all disturbing) to 4 (severely disturbing). The 10 words rated as most disturbing by each participant were then used as the personally threatening word stimuli for that participant (McNally, et al., 1994). Personally threatening stimuli used in the experiment were rated at least 2 (moderately disturbing) by the relevant participant. The 10 words from the pool of threat stimuli which were rated as of low threat value by each participant were then used as the low threat stimuli for that participant. Neutral words were alphabetically mingled with threat words and included in the rating process to ensure their neutrality and equivalent experimental exposure. Stimuli were presented across four blocks: Two blocks of 50 neutral and 50 personally threatening stimuli (personal threat blocks), and two blocks of 50 neutral and 50 low threat stimuli (low threat blocks). Stimuli were randomly presented five times per block. Half were blue, and half green, varying randomly. Stimulus duration was $200 \mathrm{~ms}$ and ISI varied randomly between 2.5 and $3.5 \mathrm{~s}$.

\subsection{Procedure}

Participants were comfortably seated in a sound-attenuated, dim room, 1-m from the computer and responded using a two-button press device with index and middle fingers. Blocks were presented twice, with different requirements. In the color task, participants ignored word meaning and indicated as quickly and accurately as possible whether each word appeared in blue or green font. In the word task, participants classified whether each word was a threat word or a non-threat word. Task sequences and response button assignment were counterbalanced.

\subsection{Electrophysiological recording}

The EEG was recorded from 19 scalp electrodes (F1, F2, Fz, F3, F4, F7, F8, Cz, C3, C4, T3, T4, T5, T6, Pz, P3, P4, O1, O2), referenced to linked ears according to the 
international 10 - 20 system (Jasper, 1958) using tin electrodes in an electrode cap (Electrocap International). The participant was grounded by a cap electrode located between Fpz and Fz. Vertical EOG was recorded from electrodes placed $1 \mathrm{~cm}$ above and below the left eye, and electrodes placed beyond the outer canthus of each eye recorded horizontal EOG. Electrode impedances were below $5 \mathrm{k} \Omega$.

\subsection{Data reduction}

ERP data were amplified with EEG and EOG gains of 20,000 and 5,000 respectively, digitized at a sampling rate of $512 \mathrm{~Hz}$ with a bandpass down $3 \mathrm{~dB}$ at 0.01 and $35 \mathrm{~Hz}$, and filtered offline with a low-pass zero-phase shift filter at $30 \mathrm{~Hz}, 48 \mathrm{~dB} /$ octave. Data were submitted to artifact rejection $( \pm 100 \mu \mathrm{V})$ and eye-movement correction (Semlitsch, Anderer, Schuster, \& Presslich, 1986) and screened for sudden, non-physiologically plausible changes and these were removed prior to ERP averaging.

Five components were quantified, with amplitudes determined relative to the $100 \mathrm{~ms}$ prestimulus baseline. Peaks were detected in specified channels where they generally showed maximal amplitude in the grand mean waveforms: $\mathrm{O} 1$ for $\mathrm{P} 1(50-120 \mathrm{~ms})$; $\mathrm{O} 2$ for $\mathrm{N} 1(90$ $160 \mathrm{~ms})$; Pz for P2 (150 - $210 \mathrm{~ms})$; Fz for N2 (180 - $400 \mathrm{~ms})$, and Pz for P3 (290 - $600 \mathrm{~ms})$. Additionally, mean slow wave amplitude was calculated between 500-900 ms. Search windows were based on visual inspection of the grand mean waveforms. ERP latencies were recorded as the time during the search window of maximal amplitude at the site where the component was quantified, and relative amplitude measures for all 11 electrodes were taken at the same post-stimulus latency (Picton et al., 2000).

\subsection{Data analysis}

For ease of reference, specific ANOVA designs are described in the relevant results sections. Due to broadly distributed effects in previous Stroop studies, we used an approach which analyzes nine sites (F3, Fz, F4, C3, Cz, C4, P3, Pz, P4), using planned contrasts within 
sagittal and lateral planes (described below), which reduces the number of statistical comparisons made while optimally identifying any anterior-posterior and hemispheric differences (Picton et al., 2000; Smith, Johnstone, \& Barry, 2004; Thomas, Gonsalvez, \& Johnstone, 2009). Within the lateral plane, two planned contrasts were computed: left (F3, $\mathrm{C} 3, \mathrm{P} 3)$ versus right $(\mathrm{F} 4, \mathrm{C} 4, \mathrm{P} 4)$ hemispheres, and the midline region $(\mathrm{Fz}, \mathrm{Cz}, \mathrm{Pz})$ versus the mean of the left and right hemispheres (as before). Within the saggital plane, the two planned contrasts computed were: frontal (F3, Fz, F4) versus parietal (P3, Pz, P4), and the central region $(\mathrm{C} 3, \mathrm{Cz}, \mathrm{C} 4)$ versus the mean of the frontal and parietal regions (as before). As the contrasts were planned and there were no more of them than the degrees of freedom for an effect, no Bonferroni-type adjustment was necessary (Tabachnick, Fidell, \& Osterlind, 2001). Greenhouse-Geisser adjustments were applied where appropriate.

Additional amplitude analyses were performed at occipital electrodes (O1 and O2) for P1 and N1, where these components were maximal. Significant differences between the three groups were followed by simple effects comparisons to determine which differences were driving the effects. ERP data were normalized using the vector scaling procedure (McCarthy $\&$ Wood, 1985), and interactions involving topography are reported only if they remained significant after normalization.

For brevity and because the focus of the study was between group differences in threat processing, only effects which involved both Threat and Group, and topographical results which aid interpretation of these results, are reported in the main ERP analyses. Effects of Task and topographical effects related to threat processing in this task are considered elsewhere (Thomas, et al., 2007). Because the primary focus was personally threatening stimuli, the main analysis included the personal threat blocks only. Where threat interactions were significant, the corresponding analysis was repeated on the low threat blocks to distinguish between personal threat and general emotionality effects. 
To assess whether group effects or interactions were related to medication status, for each clinical group separately, analyses were repeated with a between subjects factor of Medication (medicated, unmedicated). No factors involved in effects below interacted with Medication status.

\section{Results}

\subsection{Clinical characteristics}

Table 1 shows group characteristics. Fisher's exact test was used to compare group categorical variables. One-way analyses of variance (ANOVAs) were used to compare groups on age and psychometric variables. There were no significant between-group differences for age, gender or handedness. Clinical participants scored higher than HCs on all psychopathology measures. There were no significant differences between OCD and PD participants in numbers medicated or in psychopathology including depressive symptoms, excepting higher OCD symptoms in OCD participants.

\subsection{Attentional biases to threat}

Mean RTs by condition are shown in Figure 1. Attentional biases were analyzed using Group (HC, PD, OCD) x Threat (neutral, threat) x Task (color, word) ANOVAs. Mean RTs for correct responses by stimulus type and task were calculated for each participant. Extreme scores ( \pm 2 SDs from the participant's own condition mean) were excluded. Accuracy was high (98\%) and did not interact with other variables. Across tasks, there was a main effect of Group, $F(2,57)=13.03, p<.001$, driven by longer RTs in clinical groups compared with HCs $(\mathrm{OCD}$ vs. HC: $F(1,38)=7.65, p<.01$; PD vs. $\mathrm{HC}: F(1,38)=23.27, p<.001$, and longer RTs in PD than OCD, $F(1,38)=7.25, p<.05$. Group interacted with Threat, $F(2$, $57)=3.47, p<.05$, with PD participants having relatively longer RTs to threat versus neutral words compared to OCD, $F(1,38)=8.96, p<.01$ and $\mathrm{HC}, F(1,38)=4.72, p=.05$, 
participants. RTs overall were shorter to threat than neutral words, $F(1,57)=8.2, p<.01$. This differed by Task, $F(1,57)=29.73, p<.001$, with shorter RTs to threat than neutral words during word classification, and the reverse during color naming.

Grand mean waveforms by Group and Task are shown in Figures 2-3. ERP amplitudes for each component were analyzed using a Group (HC, PD, OCD) x Task (color, word) x Threat (neutral, threat) x Sagittal (frontal, central, parietal) x Lateral (left, midline, right) ANOVA.

Amplitudes: For P1, the Group by Threat interaction was significant, $F(2,57)=4.4, p$ $<.05$, driven by larger P1 to threat versus neutral words in the OCD, compared to HC, F (1, $38)=5.3, p<.05$, and PD, $F(1,38)=6.87, p<.05$, groups (Figure 4). A Group $\mathrm{x}$ Threat $\mathrm{x}$ Task interaction, $F(2,57)=3.31, p<.05$, was driven by threat $>$ neutral $\mathrm{P} 1$ in OCD across tasks, versus higher P1 in HCs to threat words in the word task only $(\mathrm{OCD}$ vs. $\mathrm{HC}: F(1,38)=$ $7.65, p<.01$ ). There was a Group by Sagittal (quadratic) effect, $F(2,57)=10.2, p<.001$, with both clinical groups having an atypical P1 topography in terms of reduced fronto-parietal versus central P1 amplitude $(\mathrm{PD}$ vs $\mathrm{HC}, F(1,38)=17.9, p<.001$; OCD vs. $\mathrm{HC}, F(1,38)=$ $8.4, p<.01)$. The Threat by Sagittal (quadratic) effect was significant, $F(2,57)=5.1, p<.05$, with higher fronto-parietal versus central amplitude to threat than neutral words. The Sagittal effect was significant, with higher P1 amplitude at parietal than frontal electrodes, $F(1,57)=$ $86.46, p<.0001$. The Group by Threat by Task interaction for P1 was also significant at the $\mathrm{O} 1$ and $\mathrm{O} 2$ electrodes, $F(2,57)=4.85, p<.05$.

Latencies: Mean ERP latencies for effects and interactions involving Group are shown in Figure 5. For P1, there was a Group by Threat interaction, $F(2,57)=4.79, p<.05$, driven by shorter P1 to threat than neutral words in the PD versus $\mathrm{HC}, F(1,38)=6.97, p<.05$, and OCD, $F(1,38)=6.89, p<.05$, groups. A Group by Threat by Task interaction, $F(2,57)=$ $7.26, p<.05$, indicated that this effect was greater in the color than word task in PD versus 
HCs, $F(1,38)=7.6, p<.01$, and OCD, $F(1,38)=7.26, p<.05$. For N1, a Group by Threat interaction, $F(2,57)=4.43, p<.05$, was driven by longer $\mathrm{N} 1$ to threat than neutral words in the OCD versus the PD, $F(1,38)=9.5, p<.01$, and $\mathrm{HC}$ groups, $F(1,38)=4.17, p<.05$. For the remaining components, there were no significant interactions involving both Group and Threat.

\subsection{Emotional Stroop interference}

To determine whether there was an emotional Stroop RT effect, and to enable comparison with previous emotional Stroop RT studies, which typically do not include a comparison word task, we conducted a Group (HC, PD, OCD) x Threat (neutral, threat) ANOVA on the RT data for the color-naming task only. There was a main effect of threat, $F$ $(1,57)=8.21, p<.01$. This was qualified by a Group by Threat interaction, $F(2,57)=4.45$, $p<.05$, which was driven by longer RTs to color name threat words (i.e. an emotional Stroop effect) in the PD group relative to the HCs, $F(1,38)=15.52, p<.0001$, and OCD group $F(1$, $38)=14.07, p<.0001$. Interference scores were calculated by subtracting each participant's mean color naming RTs for neutral words from those for personally threatening words. Participants with positive interference scores were allocated to an Interference group and others to a Non-interference group (Pérez-Edgar \& Fox, 2003). Emotional Stroop RT interference did not neatly overlap with clinical status, with 17 participants with PD, 10 with OCD and eight HCs were allocated to the Interference group using this method. Therefore to examine ERP correlates of emotional Stroop interference we conducted a further, focused analysis of the color-naming task with interference status (rather than clinical group) as a between-subjects variable. Across groups, 38 participants with positive interference scores were allocated to the Interference group and 22 with negative-zero interference scores to the 
Non-interference group 1 (Figure 6). Because we determined group membership based on a somewhat arbitrary cut off used in previous research (Pérez-Edgar \& Fox, 2003), we examined whether between-group RT differences were statistically significant. Emotional Stroop RT interference was analyzed in an ANOVA with Interference group (no interference, interference) as the between and Threat (neutral, threat) as the within subjects variables, focused on the RTs for the color-naming task only. RTs overall were longer in the Interference than Non-interference groups, $F(1,58)=5.7, p<.01$, and longer overall to threat than neutral words, $F(1,58)=9.09, p<.01$. These effects were qualified by an Interference by Threat interaction, $F(1,58)=41.42, p<.0001$, confirming that the Interference group had longer RTs to color name threat versus neutral words. For the remaining components, there were no significant interactions involving both Group and Threat.

Grand mean waveforms by Interference status in the emotional Stroop task are shown in Figure 6. ERPs were analyzed in an ANOVA with Interference status (interference, no interference) as between, and Threat, Sagittal and Lateral factors (as before) as within, subjects variables.

P1: Amplitude interacted with Interference status, with larger P1 to threat than neutral stimuli occurring only in the Interference group, $F(1,58)=4.66, p<.05$ (Figure 6). For P3, Threat differed by Interference status, $F(1,58)=4.33, p<.05$, with the Interference group having a Threat $>$ Neutral P3 and the Non-interference group having the reverse effect.

\subsection{Low threat analysis}

Analyses were repeated on the low threat blocks. For the low threat versus neutral

${ }^{1}$ Results were virtually identical using median split or a positive interference score cut off, hence we followed an approach used previously (Pérez-Edgar \& Fox, 2003). 
words, none of the interactions above was significant ( $p>.05$ in all cases).

\subsection{Relationships between variables}

We conducted Pearson correlations between the above significant ERP/ behavioral findings and symptom severity. P1 amplitude to threat words in both the color, $r(58)=0.47$, $p<.05$, and word, $r(58)=0.47, p<.05$, tasks correlated positively with Padua total scores. Across groups, emotional Stroop RT interference correlated positively with BSI Phobic anxiety, $r(58)=0.28, p<.05$.

\section{Discussion}

We present the first comprehensive ERP examination of an emotional word Stroop task in participants diagnosed with an anxiety or obsessive-compulsive disorder. Additionally, this is to our knowledge the first ERP study of attentional bias to threat in OCD. The high temporal resolution of ERPs localized neural changes associated with biases and interference to discrete information-processing stages.

\subsection{Attentional biases to threat}

In both clinical groups there were ERP indications of facilitated attention to threat versus neutral stimuli. There were also indications that the nature of enhanced attention to threat differed between the two clinical groups. These results appear to be consistent with an analogous fMRI study in these disorders (van den Heuvel, et al., 2005) which found neural indications of disorder-specific attentional biases to threat between PD and OCD. In the current study, participants with PD had shorter ERP latencies to threat than neutral words during sensory (P1) processing. P1 indexes visual attention capture processes (Carretié, et al., 2009; Hopfinger \& Mangun, 2001; Smith, et al., 2003). Faster capture of attention by fearrelevant stimuli may indicate their extremely efficient detection (Mathews \& Mackintosh, 1998; Ohman, Flykt, \& Esteves, 2001), or hypervigilance. 
In OCD, ERPs indicated symptom-related augmentation of sensory (P1) attention to threat, relative to other groups. P1 amplitude increases with attention to visual stimuli, with recruitment of extrastriate neurons in the visual cortex (Carretié, et al., 2009; Hopfinger \& Mangun, 2001; Martinez, et al., 1999; Smith, et al., 2003). P1 enhancement to negative stimuli may reflect rapid threat evaluation processes mediated by primitive affective systems (Cacioppo \& Gardner, 1999; Smith, Cacioppo, Larsen, \& Chartrand, 2003; van Hooff, et al., 2008; Vuilleumier, 2005), including reentrant projections from the amygdala to sensory cortices (Pizzagalli, Regard, \& Lehmann, 1999), which are hypersensitive in anxiety (Holmes, Nielsen, \& Green, 2008). As with previous studies, P1 was not generally enhanced to negative stimuli in HCs (Bar-Haim, et al., 2005; Junghöfer, et al., 2001; Olofsson \& Polich, 2007; Qin \& Han, 2009; Thomas, et al., 2007) or in PD (Pauli, Amrhein, Mühlberger, Dengler, \& Wiedemann, 2005; Pauli, Dengler, et al., 2005; Pauli, et al., 1997; Windmann, et al., 2002).

P1 amplitude effects to threat stimuli in the current study were not confined to the occipital electrodes but present more broadly across the scalp. While the broad nature of the P1 effects may seem surprising, previous ERP research with emotional stimuli has also found significant effects of emotion on P1 amplitude across broad scalp locations (Bernat, Bunce, \& Shevrin, 2001; Carretié, et al., 2004; van Hooff, Dietz, Sharma, \& Bowman, 2008), including pre-frontal sites ( Carretié, et al., 2004). ERP findings are also supported by intracranial evidence of heightened processing of emotionally aversive stimuli in human prefrontal cortex at around the same (120 ms) latency (Kawasaki et al., 2001). The amygdala interacts with many attention-related and higher-order areas of the brain (LeDoux, 2000) and such early effects of threat are proposed to reflect rapid top-down modulation of visual information processing facilitated by the amygdala (Luis Carretié, et al., 2004). This is consistent with the P1 component being sensitive to both stimulus-bound and top-down attentional factors 
(Klimesch, 2011). In the grand mean waveforms, at the latency of peak of the occipital P1, there is a polarity shift with the P1 becoming more negative towards the anterior scalp, as noted in many previous studies (see Carretié et al., 2009; Carretié, Hinojosa, Martín-Loeches, Mercado, \& Tapia, 2004). Both clinical groups showed atypical topography of $\mathrm{P} 1$. The $\mathrm{P} 1$ is mediated by cholinergic activity (see Leppänen, Moulson, Vogel-Farley, \& Nelson, 2007; Skinner et al., 1999) and the atypical topography of P1 in both clinical groups indicates the possibility of general anomalies in early visual attention, which may be linked to cholinergic function. Many previous ERP studies of emotional stimuli report only occipital analyses of P1. The current results indicate that further research is warranted into the complexities of threat processing, around the P1 latency, in clinically anxious participants.

OCD participants also had longer N1 latency to threat (versus neutral) words compared to other groups. The N1 originates in multiple generators in the occipito-parietal, occipito-temporal, and possibly frontal cortex (Clark, Fan, \& Hillyard, 1994). It indexes effortful stimulus discrimination (Vogel \& Luck, 2000) and N1 latency increases with processing effort (Callaway \& Halliday, 1982). Longer N1 latencies to complex auditory stimuli have been reported in OCD relative to $\mathrm{HCs}$, interpreted as a sign of impairment in early processing of complex stimuli including evaluating the significance of the stimuli (Morault, et al., 1997). The current results extend the N1 finding to visual and threatening stimuli, indicating prolonged, effortful processing of threat words in OCD during stimulus discrimination stages, following enhanced early (P1) processing of threat stimuli. As there was no indication of longer N1 latencies to threat stimuli in the PD group, the current results may represent effortful control strategies in OCD (Ciesielski, et al., 2005) to inhibit early attentional biases to threat stimuli. Such effortful control strategies could potentially contribute to the diminished emotional Stroop interference effects in participants with OCD, however further research is needed. 
The presence of attentional bias to threat in OCD has been doubted due to inconsistent results in RT studies (Moritz, et al., 2004; Summerfeldt \& Endler, 1998). OCD ERP research focusses on content-independent anomalies involving attention to neutral stimuli. This first ERP study, however, indicates early attentional biases to threat at a neural level in OCD as well as in PD, relative to HCs. In both disorders enhanced amygdala activation occurs in the presence of threat stimuli (van den Heuvel, et al., 2005), and taken together, the results may reflect hypersensitivity of limbic-mediated threat evaluation processes. The results are relevant to long term controversies regarding the classification of OCD as an anxiety disorder (Starcevic, 2008), and support a need for more nuanced research into threat processing in OCD.

In PD, paradoxically, P1 latency was further speeded to threat words when participants were instructed to ignore word meaning. Additionally, the larger P1 amplitude to threat occurred across tasks in OCD but only when threat content was task relevant in HCs. This may indicate greater visual sensitivity to unattended stimuli in PD and OCD (Caldirola et al., 2011), possibly facilitated by the amygdala (Phelps \& LeDoux, 2005). Rapid and automatic processing of threat cues in PD is proposed to lead to panic attacks which are perceived as spontaneous. For example, individuals with PD may experience panic attacks following the unconscious processing of bodily sensations such as palpitations (Clark, 1986). The P1 ERP indications of preferential processing of threat stimuli in both PD and OCD may represent attentional processes which contribute to the automatic and uncontrollable nature of symptoms in these disorders.

\subsubsection{Emotional Stroop interference}

Consistent with previous studies the PD (Lundh, et al., 1999; McNally, et al., 1994; McNally, Kaspi, et al., 1990) but not the OCD (Kampman, et al., 2002; Kyrios \& Iob, 1998; McNally, Riemann, et al., 1990; Moritz, et al., 2008; Moritz, et al., 2004; van den Heuvel, et 
al., 2005) group showed significant emotional Stroop interference. Interference correlated with the BSI Phobic anxiety scale which targets agoraphobic fears (Derogatis \& Melisaratos, 1983), reinforcing the link to PD. Interference effects may differ from clinical status as they may also reflect both vulnerability towards clinical anxiety (Andrew Mathews \& MacLeod, 2005). Because clinical and interference statuses did not fully overlap, we also investigated neural changes by interference status. While early (P1) attentional biases to threat were present in both anxious groups, participants with emotional Stroop interference manifested both heightened sensory and ongoing cognitive processing of threat stimuli. The timing of effects is consistent with models of emotional attention which implicate both bottom-up processes biasing attention towards salient stimuli (Adolphs, Tranel, Damasio, \& Damasio, 1995; Browning, Holmes, \& Harmer, 2010; Davis \& Whalen, 2001) and top-down control processes responsible for task-relevant focus (Bishop, 2007; Browning, et al., 2010). The current results lead to the suggestion that sensory threat biases are a core feature of both PD and OCD, whereas emotional Stroop interference is a partially overlapping phenomenon involving both heightened sensory attention towards, and central-cognitive elaboration of, threatening stimuli.

The current results may have clinical implications. Attentional biases to threat may be causally related to anxiety disorders (Browning, et al., 2010; Fox, et al., 2010), and they reduce with successful interventions (Browning, et al., 2010). Pharmacological and psychological interventions may preferentially target sensory and cognitive attentional deployment towards threat respectively (Browning, et al., 2010; DeRubeis, Hollon, \& Siegle, 2008), and combined treatments may have additive effects. Novel treatments targeting early attentional biases are currently emerging (Cisler \& Koster, 2010). Further studies are needed to determine if individuals' attentional deployment to threat predicts specific therapeutic outcomes. 


\subsection{Further findings}

During the word-relevant condition, all groups were faster at categorizing threat than neutral words. This supports preferential processing rather than effortful avoidance accounts of emotional Stroop interference (Bar-Haim, et al., 2007; Kyrios \& Iob, 1998), as effortful avoidance of threat stimuli would presumably be equivalent or greater during conditions requiring explicit attention towards threat. Faster RTs to respond to task relevant threat stimuli have been reported elsewhere in healthy and clinically anxious participants (Kolassa, et al., 2005). Effects occurred only for personally threatening stimuli, and did not occur for words drawn from the same threat pool which participants had rated as being of low threat value to them personally. This leads to the suggestion that ERP and behavioral results related to threat appraisal rather than the general emotional value of word stimuli, and highlights the importance of tailored stimuli when investigating attentional biases towards threat.

\subsection{Caveats and future directions}

Many clinical participants were taking medication. While we controlled for this in the analysis, it is possible that medication affected experimental variables. Also, while both clinical groups had primary diagnoses of either PD or OCD, many participants had comorbidities when we conducted thorough assessments of symptoms. It is therefore possible that comorbid symptoms influenced the results. In particular, we need to consider the possibility that elevated trait or state anxiety in the clinical groups accounted for the early attentional biases to threat in the ERP data, rather than PD or OCD-specific symptoms. A strength of the current study was to include two clinical groups with similar levels of psychopathology and medication use, and differing significantly only in their specific symptom profiles (e.g. the OCD group had higher levels of OCD-specific psychopathology). While general symptom severity was similar across clinical groups, the specific nature attentional biases and interference differed between clinical groups, with faster (P1) 
processing in PD followed by behavioral interference, and more intensive (P1-N1) processing in OCD. These factors raise the likelihood that differential results in the clinical groups were due to the differences in primary diagnoses between the clinical groups. Many previous ERP studies report or fail to mention comorbidities of clinical patients (Endrass, Klawohn, Schuster, \& Kathmann, 2008; Johannes et al., 2001; Kim et al., 2003; Kim et al., 2006; Kivircik, et al., 2003; Mueller, et al., 2009; Oades, Dittmann-Balcar, et al., 1996; Schall, Schön, Zerbin, Eggers, \& Oades, 1996; Thibault et al., 2008). Future research with nonmedicated participants with pure diagnoses and no comorbidities would be ideal, however practical and ethical difficulties and high comorbidities have contributed to the use of medicated participants and small sample sizes, particularly in OCD research (Muller \& Roberts, 2005), and remain as ongoing challenges.

In conclusion, this study offers the first direct evidence of heightened sensory attention to threat in PD and OCD. These preliminary results support the need for more nuanced investigations of attentional biases in these conditions. Additionally, this is the first clinical study to provide physiological evidence to localize emotional word Stroop interference in clinically anxious participants to discrete sensory and cognitive stages. The current results support and extend conceptualizations of threat-related biases and interference as involving dissociable sensory and cognitive components (Cisler \& Koster, 2010; Klumpers et al., 2010; Mueller, et al., 2009), which may be disorder specific (van den Heuvel, et al., 2005). While heightened sensory attention to threat appears to be a characteristic of both PD and OCD, emotional Stroop interference involves additional, cognitive, elaboration of threat. 


\section{References}

Adler, C. M., McDonough-Ryan, P., Sax, K. W., Holland, S. K., Arndt, S., \& Strakowski, S. M. (2000). fMRI of neuronal activation with symptom provocation in unmedicated patients with obsessive compulsive disorder. Journal of Psychiatric Research, 34, 317-324.

Adolphs, R., Tranel, D., Damasio, H., \& Damasio, A. R. (1995). Fear and the human amygdala. The Journal of neuroscience : the official journal of the Society for Neuroscience, 15, 5879-5891.

Algom, D., Chajut, E., \& Lev, S. (2004). A rational look at the emotional stroop phenomenon: a generic slowdown, not a stroop effect. Journal of Experimental Psychology: General, 133, 323.

APA. (2000). Diagnostic and Statistical Manual of Mental Disorders (4th Ed., Text revision ed.). Washington, D.C.: American Psychiatric Association.

Bar-Haim, Y., Lamy, D., \& Glickman, S. (2005). Attentional bias in anxiety: A behavioral and ERP study. Brain and Cognition, 59, 11-22.

Bar-Haim, Y., Lamy, D., Pergamin, L., Bakermans-Kranenburg, M. J., \& van Ijzendoorn, M. H. (2007). Threat-related attentional bias in anxious and nonanxious individuals: A meta-analytic study. Psychological Bulletin, 133, 1.

Baumeister, R., Bratslavsky, E., Finkenauer, C., \& Vohs, K. (2001). Bad is stronger than good. Review of general psychology, 5, 323-370.

Bayer, M., Sommer, W., \& Schacht, A. (2012). P1 and beyond: Functional separation of multiple emotion effects in word recognition. Psychophysiology, 49, 959-969.

Bernat, E., Bunce, S., \& Shevrin, H. (2001). Event-related brain potentials differentiate positive and negative mood adjectives during both supraliminal and subliminal visual processing. International Journal of Psychophysiology, 42, 11-34.

Bishop, S. J. (2007). Neurocognitive mechanisms of anxiety: an integrative account. Trends in Cognitive Sciences, 11, 307-316.

Breiter, H. C., \& Rauch, S. L. (1996). Functional MRI and the Study of OCD: From Symptom Provocation to Cognitive-Behavioral Probes of Cortico-Striatal Systems and the Amygdala. NeuroImage, 4, S127-S138.

Brown, C., El-Deredy, W., \& Blanchette, I. (2010). Attentional modulation of visual-evoked potentials by threat: Investigating the effect of evolutionary relevance. Brain and Cognition. 74, 281-287.

Browning, M., Holmes, E. A., \& Harmer, C. J. (2010). The modification of attentional bias to emotional information: A review of the techniques, mechanisms, and relevance to emotional disorders. Cognitive, Affective, \& Behavioral Neuroscience, 10, 8-20.

Burns, G. L., Keortge, S. G., Formea, G. M., \& Sternberger, L. G. (1996). Revision of the Padua Inventory of obsessive compulsive disorder symptoms: distinctions between worry, obsessions, and compulsions. Behavior Research and Therapy, 34, 163-173.

Cacioppo, J., \& Gardner, W. (1999). Emotion. Annual Review of Psychology, 50, 191-214.

Caldirola, D., Teggi, R., Bondi, S., Lopes, F. L., Grassi, M., Bussi, M., \& Perna, G. (2011). Is there a hypersensitive visual alarm system in panic disorder? Psychiatry Research, 187, 387-391.

Callaway, E., \& Halliday, R. (1982). The effect of attentional effort on visual evoked potential N1 latency. Psychiatry Research, 7, 299-308.

Carretié, L., Hinojosa, J. A., López-Martín, S., Albert, J., Tapia, M., \& Pozo, M. A. (2009). Danger is worse when it moves: Neural and behavioral indices of enhanced attentional capture by dynamic threatening stimuli. Neuropsychologia, 47, 364-369.

Carretié, L., Mercado, F., Tapia, M., \& Hinojosa, J. A. (2001). Emotion, attention, and the 
'negativity bias', studied through event-related potentials. International Journal of Psychophysiology, 41(1), 75-85.

Chen, X.-L., Xie, J.-X., Han, H.-B., Cui, Y.-H., \& Zhang, B.-Q. (2004). MR perfusionweighted imaging and quantitative analysis of cerebral hemodynamics with symptom provocation in unmedicated patients with obsessive-compulsive disorder. Neuroscience Letters, 370, 206-211.

Ciesielski, K. T., Hamalainen, M. S., Lesnik, P. G., Geller, D. A., \& Ahlfors, S. P. (2005). Increased MEG activation in OCD reflects a compensatory mechanism specific to the phase of a visual working memory task. NeuroImage, 24, 1180-1191.

Cisler, J. M., \& Koster, E. H. W. (2010). Mechanisms of attentional biases towards threat in anxiety disorders: An integrative review. Clinical Psychology Review, 30, 203-216.

Clark, D. M. (1986). A cognitive approach to panic. Behavior Research and Therapy, 24, 461-470.

Clark, V. P., Fan, S., \& Hillyard, S. A. (1994). Identification of early visual evoked potential generators by retinotopic and topographic analyses. Human Brain Mapping, 2, 170187.

Conrad, M., Recio, G., \& Jacobs, A. M. (2011). The Time Course of Emotion Effects in First and Second Language Processing: A Cross Cultural ERP Study with German-Spanish Bilinguals. Frontiers in psychology, 2.

Dalgleish, T., \& Watts, F. N. (1990). Biases of attention and memory in disorders of anxiety and depression. Clinical Psychology Review, 10, 589-604.

Davis, M., \& Whalen, P. J. (2001). The amygdala: vigilance and emotion. Molecular Psychiatry, 6, 13-34.

Derogatis, L. R., \& Melisaratos, N. (1983). The Brief Symptom Inventory: an introductory report. Psychological Medicine, 13, 595-605.

DeRubeis, R. J., Hollon, S. D., \& Siegle, G. J. (2008). Cognitive therapy versus medication for depression: treatment outcomes and neural mechanisms. [Clinical report]. Nature Reviews Neuroscience, 9, 788.

Di Russo, F., Zaccara, G., Ragazzoni, A., \& Pallanti, S. (2000). Abnormal visual eventrelated potentials in obsessive-compulsive disorder without panic disorder or depression comorbidity. Journal of Psychiatric Research, 34, 75-82.

Duncan-Johnson, C. C., \& Donchin, E. (1982). The P300 component of the event-related brain potential as an index of information processing. Biological Psychology, 14, 152.

Endrass, T., Klawohn, J., Schuster, F., \& Kathmann, N. (2008). Overactive performance monitoring in obsessive-compulsive disorder: ERP evidence from correct and erroneous reactions. Neuropsychologia, 46, 1877-1887.

Fisher, J. E., Sass, S. M., Heller, W., Silton, R. L., Edgar, J. C., Stewart, J. L., \& Miller, G. A. (2010). Time course of processing emotional stimuli as a function of perceived emotional intelligence, anxiety, and depression. Emotion, 10, 486.

Foa, E. B., Ilai, D., McCarthy, P. R., Shoyer, B., \& Murdock, T. B. (1993). Information processing in obsessive-compulsive disorder. Cognitive Therapy and Research, 17, 173-189.

Fox, E., Cahill, S., \& Zougkou, K. (2010). Preconscious Processing Biases Predict Emotional Reactivity to Stress. [doi: DOI: 10.1016/j.biopsych.2009.11.018]. Biological Psychiatry, 67, 371-377.

Fox, E., Russo, R., Bowles, R., \& Dutton, K. (2001). Do Threatening Stimuli Draw or Hold Visual Attention in Subclinical Anxiety? Journal of Experimental Psychology, 130, 681-700.

Frühholz, S., Jellinghaus, A., \& Herrmann, M. (2011). Time course of implicit processing 
and explicit processing of emotional faces and emotional words. Biological psychology, 87, 265-274.

Gohle, D., Juckel, G., Mavrogiorgou, P., Pogarell, O., Mulert, C., Rujescu, D., Hegerl, U. (2008). Electrophysiological evidence for cortical abnormalities in obsessivecompulsive disorder - A replication study using auditory event-related P300 subcomponents. Journal of Psychiatric Research, 42, 297-303.

Goodman, W. K., Price, L. H., Rasmussen, S. A., Mazure, C., Fleischmann, R. L., Hill, C. L., Charney, D. S. (1989). The Yale-Brown obsessive compulsive scale. Archives of General Psychiatry, 46, 1006-1011.

Herrmann, M. J., Jacob, C., Unterecker, S., \& Fallgatter, A. J. (2003). Reduced responseinhibition in obsessive-compulsive disorder measured with topographic evoked potential mapping. Psychiatry Research, 120, 265-271.

Holmes, A., Nielsen, M., \& Green, S. (2008). Effects of anxiety on the processing of fearful and happy faces: An event-related potential study. Biological psychology, 77, 159173.

Hopfinger, J. B., \& Mangun, G. R. (2001). Tracking the influence of reflexive attention on sensory and cognitive processing. Cognitive, Affective, \& Behavioral Neuroscience, 1 , 56.

Jasper, H. H. (1958). The ten-twenty electrode system of the International Federation. Electroencephalography and clinical Neurophysiology, 10, 371-375.

Johannes, S., Weber, A., Müller-Vahl, K. R., Kolbe, H., Dengler, R., \& Münter, T. F. (1999). Evidence for changed recognition of emotionally charged words in patients with Gilles de la Tourette Syndrome and obsessive-compulsive disorder. Cognitive Neuropsychiatry, 4, 37-53.

Johannes, S., Wieringa, B. M., Nager, W., Rada, D., Dengler, R., Emrich, H. M., . . . Dietrich, D. E. (2001). Discrepant target detection and action monitoring in obsessivecompulsive disorder. Psychiatry Research: Neuroimaging, 108, 101-110.

Junghöfer, M., Bradley, M. M., Elbert, T. R., \& Lang, P. J. (2001). Fleeting images: A new look at early emotion discrimination. Psychophysiology, 38, 175-178.

Kampman, M., Keijsers, G. P. J., Verbraak, M. J. P. M., Naring, G., \& Hoogduin, C. A. L. (2002). The emotional Stroop: a comparison of panic disorder patients, obsessivecompulsive patients, and normal controls, in two experiments. Journal of Anxiety Disorders, 16, 425-441.

Kawasaki, H., Adolphs, R., Kaufman, O., Damasio, H., Damasio, A. R., Granner, M., .. . Howard, M. A. (2001). Single-neuron responses to emotional visual stimuli recorded in human ventral prefrontal cortex. Nature neuroscience, 4, 15-16.

Keil, A., Bradley, M. M., Hauk, O., Rockstroh, B., Elbert, T., \& Lang, P. J. (2002). Large scale neural correlates of affective picture processing. Psychophysiology, 39, 641-649.

Kim, M.-S., Kang, S.-S., Youn, T., Kang, D.-H., Kim, J.-J., \& Kwon, J. S. (2003). Neuropsychological correlates of P300 abnormalities in patients with schizophrenia and obsessive-compulsive disorder. Psychiatry Research: Neuroimaging, 123, 109123.

Kim, M.-S., Kim, Y. Y., Kim, E. N., Lee, K. J., Ha, T. H., \& Kwon, J. S. (2006). Implicit and explicit memory in patients with obsessive-compulsive disorder: An event-related potential study. Journal of Psychiatric Research, 40, 541-549.

Kindt, M., \& Brosschot, J. F. (1999). Cognitive bias in spider-phobic children: Comparison of a pictorial and a linguistic spider Stroop. Journal of Psychopathology and Behavioral Assessment, 21, 207-220.

Kissler, J., Herbert, C., Winkler, I., \& Junghofer, M. (2009). Emotion and attention in visual word processing--An ERP study. [doi: DOI: 10.1016/j.biopsycho.2008.03.004]. 
Biological Psychology, 80, 75-83.

Kivircik, B. B., Yener, G. G., Alptekin, K., \& Aydin, H. (2003). Event-related potentials and neuropsychological tests in obsessive-compulsive disorder. Progress In NeuroPsychopharmacology \& Biological Psychiatry, 27, 601-606.

Klimesch, W. (2011). Evoked alpha and early access to the knowledge system: The P1 inhibition timing hypothesis. Brain research, 1408, 52-71.

Klumpers, F., Raemaekers, M. A. H. L., Ruigrok, A. N. V., Hermans, E. J., Kenemans, J. L., \& Baas, J. M. P. (2010). Prefrontal Mechanisms of Fear Reduction After Threat Offset. Biological Psychiatry, 68, 1031-1038.

Kok, A. (2001). On the utility of $\mathrm{P} 3$ amplitude as a measure of processing capacity. Psychophysiology, 38, 557-577.

Kolassa, I.-T., \& Miltner, W. H. (2006). Psychophysiological correlates of face processing in social phobia. Brain research, 1118, 130-141.

Kolassa, I. T., Musial, F., Mohr, A., Trippe, R. H., \& Miltner, W. H. (2005).

Electrophysiological correlates of threat processing in spider phobics. Psychophysiology, 42, 520-530.

Kuelz, A. K., Hohagen, F., \& Voderholzer, U. (2004). Neuropsychological performance in obsessive-compulsive disorder: a critical review. Biological Psychology, 65, 185-236.

Kyrios, M., \& Iob, M. A. (1998). Automatic and Strategic Processing in ObsessiveCompulsive Disorder: Attentional Bias, Cognitive Avoidance or More Complex Phenomena? Journal of Anxiety Disorders, 12, 271-292.

Lavy, E., van den Hout, M., \& Arntz, A. (1993). Attentional bias and spider phobia: Conceptual and clinical issues. Behavior Research and Therapy, 31, 17-24.

Lavy, E., Van Oppen, P., \& Van Den Hout, M. (1994). Selective processing of emotional information in obsessive compulsive disorder. Behavior Research and Therapy, 32, 243-246.

Leppänen, J. M., Moulson, M. C., Vogel-Farley, V. K., \& Nelson, C. A. (2007). An ERP Study of Emotional Face Processing in the Adult and Infant Brain. Child development, 78, 232-245.

Li, W., Zinbarg, R., \& Paller, K. (2007a). Trait anxiety modulates supraliminal and subliminal threat: Brain potential evidence for early and late processing influences. Cognitive, Affective, \&amp; Behavioral Neuroscience, 7, 25-36.

Liotti, M., Woldorff, M. G., PerezIII, R., \& Mayberg, H. S. (2000). An ERP study of the temporal course of the Stroop color-word interference effect. Neuropsychologia, 38, 701-711.

Lundh, L.-G., Wikstrom, J., Westerlund, J., \& Ost, L.-G. (1999). Preattentive Bias for Emotional Information in Panic Disorder With Agoraphobia. Journal of Abnormal Psychology, 108, 222-232.

MacLeod, C. (2004). The causal status of anxiety-linked attentional and interpretive bias. Cognition, emotion, and psychopathology: theoretical, empirical, and clinical directions, 172.

Malloy, P., Rasmussen, S., Braden, W., \& Haier, R. J. (1989). Topographic evoked potential mapping in obsessive-compulsive disorder: Evidence of frontal lobe dysfunction. Psychiatry Research, 28, 63-71.

Martinez, A., Anllo-Vento, L., Sereno, M. I., Frank, L. R., Buxton, R. B., Dubowitz, D., . . . Hillyard, S. A. (1999). Involvement of striate and extrastriate visual cortical areas in spatial attention. Nature Neuroscience, 2, 364-369.

Mathews, A., \& Mackintosh, B. (1998). A cognitive model of selective processing in anxiety. Cognitive Therapy and Research, 22, 539-560.

Mathews, A., \& MacLeod, C. (2005). Cognitive vulnerability to emotional disorders. Annual 
review of clinical psychology, 1, 167-195.

McCarthy, G., \& Wood, C. C. (1985). Scalp distributions of event-related potentials: An ambiguity associated with analysis of variance models. Electroencephalography and Clinical Neurophysiology/Evoked Potentials Section, 62, 203-208.

McNally, R. J., Amir, N., Louro, C. E., Lukach, B. M., Riemann, B. C., \& Calamari, J. E. (1994). Cognitive processing of idiographic emotional information in panic disorder. Behavior Research and Therapy, 32, 119-122.

McNally, R. J., Kaspi, S. P., Riemann, B. C., \& Zeitlin, S. B. (1990). Selective Processing of Threat Cues in Posttraumatic Stress Disorder,. Journal of Abnormal Psychology, 99, 398-402.

McNally, R. J., Riemann, B. C., \& Kim, E. (1990). Selective processing of threat cues in panic disorder. Behavior Research and Therapy, 28, 407-412.

Metzger, L. J., Orr, S. P., Lasko, N. B., McNally, R., \& Pittman, R. K. (1997). Seeking the source of emotional stroop interference effects in PTSD: A study of P3s to traumatic words. Integrative Physiological and Behavioral Science, 32, 43-51.

Miyata, Matsunaga, Kiriike, Iwasaki, Takei, \& Yamagami. (1998). Event-related potentials in patients with obsessive-compulsive disorder. Psychiatry and Clinical Neurosciences, 52, 513-518.

Mogg, K., Bradley, B., De Bono, J., \& Painter, M. (1997). Time course of attentional bias for threat information in non-clinical anxiety. Behavior Research and Therapy, 35, 297303.

Mogg, K., Bradley, B. P., De Bono, J., \& Painter, M. (1997). Time course of attentional bias for threat information in non-clinical anxiety. Behavior Research and Therapy, 35, 297-303.

Morault, P., Bourgeois, M., Laville, J., Bensch, C., \& Paty, J. (1997). Psychophysiological and Clinical Value of Event-Related Potentials in Obsessive-Compulsive Disorder. Biological Psychiatry, 42, 46-56.

Moritz, S., Fischer, B. K., Hottenrott, B., Kellner, M., Fricke, S., Randjbar, S., \& Jelinek, L. (2008). Words may not be enough! No increased emotional Stroop effect in obsessive-compulsive disorder. Behavior Research and Therapy, 46, 1101-1104.

Moritz, S., Hottenrott, B., Randjbar, S., Klinge, R., Von Eckstaedt, F. V., Lincoln, T. M., \& Jelinek, L. (2009). Perseveration and not strategic deficits underlie delayed alternation impairment in obsessive-compulsive disorder (OCD). Psychiatry Research, 170, 6669.

Moritz, S., Jacobsen, D., Kloss, M., Fricke, S., Rufer, M., \& Hand, I. (2004). Examination of emotional Stroop interference in obsessive-compulsive disorder. Behavior Research and Therapy, 42, 671-682.

Moritz, S., \& von Mühlenen, A. (2008). Investigation of an attentional bias for fear-related material in obsessive-compulsive checkers. Depression and Anxiety, 25, 225-229.

Moritz, S., Von Muhlenen, A., Randjbar, S., Fricke, S., \& Jelinek, L. (2009). Evidence for an attentional bias for washing- and checking-relevant stimuli in obsessive-compulsive disorder. Journal of the International Neuropsychological Society, 15, 365-371.

Mueller, E., Hofmann, S., Santesso, D., Meuret, A., Bitran, S., \& Pizzagalli, D. A. (2009). Electrophysiological evidence of attentional biases in social anxiety disorder. Psychological Medicine, 39, 1141-1152.

Mueller, E. M., Hofmann, S. G., Santesso, D. L., Meuret, A. E., Bitran, S., \& Pizzagalli, D. A. (2009). Electrophysiological evidence of attentional biases in social anxiety disorder. Psychological Medicine, 39, 1141-1152.

Muller, J., \& Roberts, J. (2005). Memory and attention in Obsessive-Compulsive Disorder: a review. Journal of Anxiety Disorders, 19, 1-28. 
Nakao, T., Nakagawa, A., Yoshiura, T., Nakatani, E., Nabeyama, M., Yoshizato, C., Kanba, S. (2005). Brain activation of patients with obsessive-compulsive disorder during neuropsychological and symptom provocation tasks before and after symptom improvement: A functional magnetic resonance imaging study. Biological Psychiatry, 57, 901-910.

Oades, R. D., Dittmann-Balcar, A., Schepker, R., Eggers, C., \& Zerbin, D. (1996). Auditory event-related potentials (ERPs) and mismatch negativity (MMN) in healthy children and those with attention-deficit or tourette/tic symptoms. Biological Psychology, 43, $163-185$.

Oades, R. D., Zerbin, D., Dittmann-Balcar, A., \& Eggers, C. (1996). Auditory event-related potential (ERP) and difference-wave topography in schizophrenic patients with/without active hallucinations and delusions: a comparison with young obsessivecompulsive disorder (OCD) and healthy subjects. International Journal of Psychophysiology, 22, 185-214.

Ohman, A., Flykt, A., \& Esteves, F. (2001). Emotion drives attention: Detecting the snake in the grass. Journal of Experimental Psychology General, 130, 466-478.

Olofsson, J., Nordin, S., Sequeira, H., \& Polich, J. (2008). Affective picture processing: An integrative review of ERP findings. Biological psychology, 77, 247-265.

Olofsson, J. K., \& Polich, J. (2007). Affective visual event-related potentials: Arousal, repetition, and time-on-task. Biological psychology, 75, 101-108.

Organisation, W. H. (1997). Composite International Diagnostic Interview: Administrator's guide and reference. Geneva World Health Organisation.

Ortigue, S., Michel, C. M., Murray, M. M., Mohr, C., Carbonnel, S., \& Landis, T. (2004). Electrical neuroimaging reveals early generator modulation to emotional words. Neuroimage, 21, 1242-1251.

Pauli, P., Amrhein, C., Mühlberger, A., Dengler, W., \& Wiedemann, G. (2005).

Electrocortical evidence for an early abnormal processing of panic-related words in panic disorder patients. International journal of psychophysiology, 57, 33-41.

Pauli, P., Dengler, W., \& Wiedemann, G. (2005). Implicit and explicit memory processes in panic patients as reflected in behavioral and electrophysiological measures. Journal of Behavior Therapy and Experimental Psychiatry, 36, 33-41.

Pauli, P., Dengler, W., Wiedemann, G., Montoya, P., Flor, H., Birbaumer, N., \& Buchkremer, G. (1997). Behavioral and neurophysiological evidence for altered processing of anxiety-related words in panic disorder. Journal of abnormal psychology, 106, 213.

Pérez-Edgar, K., \& Fox, N. A. (2003). Individual differences in children's performance during an emotional Stroop task: A behavioral and electrophysiological study. Brain and Cognition, 52, 33-51.

Phelps, E. A., \& LeDoux, J. E. (2005). Contributions of the Amygdala to Emotion Processing: From Animal Models to Human Behavior. Neuron, 48, 175-187.

Picton, T., Bentin, S., Berg, P., Donchin, E., Hillyard, S., Johnson, R., Taylor, M. (2000). Guidelines for using human event-related potentials to study cognition: Recording standards and publication criteria. Psychophysiology, 37, 127-152.

Picton, T. W. (1992). The P300 wave of the human event-related potential. Journal of Clinical Neurophysiology., 9, 456-479.

Pizzagalli, D., Regard, M., \& Lehmann, D. (1999). Rapid emotional face processing in the human right and left brain hemispheres: an ERP study. Neuroreport, 10, 2691.

Qin, J., \& Han, S. (2009). Neurocognitive mechanisms underlying identification of environmental risks. Neuropsychologia, 47, 397-405.

Rabovsky, M., Sommer, W., \& Abdel Rahman, R. (2011). Depth of Conceptual Knowledge Modulates Visual Processes during Word Reading. Journal of Cognitive 
Neuroscience, 24, 990-1005.

Rachman, S. (2007). Unwanted intrusive images in obsessive compulsive disorders. Journal of behavior therapy and experimental psychiatry, 38, 402-410.

Radua, J., van den Heuvel, O. A., Surguladze, S., \& Mataix-Cols, D. (2010). Meta-analytical comparison of voxel-based morphometry studies in obsessive-compulsive disorder vs other anxiety disorders. Archives of general psychiatry, 67, 701.

Rauch, S. L., Savage, C. R., Alpert, N. M., Fischman, A. J., \& Jenike, M. A. (1997). The Functional Neuroanatomy of Anxiety: A Study of Three Disorders Using Positron Emission Tomography and Symptom Provocation. Biological Psychiatry, 42, 446452.

Ruchsow, M., Reuter, K., Hermle, L., Ebert, D., Kiefer, M., \& Falkenstein, M. (2007). Executive control in obsessive-compulsive disorder: event-related potentials in a Go/Nogo task. Journal of Neural Transmission, 114, 1595-1601.

Sanz, M., Molina, V., Martin-Loeches, M., Calcedo, A., \& Rubia, F. J. (2001). Auditory P300 event related potential and serotonin reuptake inhibitor treatment in obsessivecompulsive disorder patients. Psychiatry Research, 101, 75-81.

Sass, S. M., Heller, W., Stewart, J. L., Silton, R. L., Edgar, J. C., Fisher, J. E., \& Miller, G. A. (2010). Time course of attentional bias in anxiety: Emotion and gender specificity. Psychophysiology, 47, 247-259.

Saxena, S., \& Rauch, S. L. (2000). Functional neuroimaging and the neuroanatomy of obsessive-compulsive disorder. Psychiatric Clinics of North America, 23(3), 563-586.

Schall, U., Schon, A., Zerbin, D., Bender, S., Eggers, C., \& Oades, R. D. (1997). A left temporal lobe impairment of auditory information processing in schizophrenia: an event-related potential study. Neuroscience Letters, 229, 25-28.

Schall, U., Schön, A., Zerbin, D., Eggers, C., \& Oades, R. D. (1996). Event-related potentials during an auditory discrimination with prepulse inhibition in patients with schizophrenia, obsessive-compulsive disorder and healthy subjects. International Journal of Neuroscience, 84, 15-33.

Scott, G. G., O'Donnell, P. J., Leuthold, H., \& Sereno, S. C. (2009). Early emotion word processing: Evidence from event-related potentials. Biological psychology, 80, 95104.

Semlitsch, H. V., Anderer, P., Schuster, P., \& Presslich, O. (1986). A solution for reliable and valid reduction of ocular artifacts, applied to the P300 ERP. Psychophysiology, 23, 695-703.

Skinner, R. D., Rasco, L. M., Fitzgerald, J., Karson, C. N., Matthew, M., Williams, D. K., \& Garcia-Rill, E. (1999). Reduced sensory gating of the P1 potential in rape victims and combat veterans with posttraumatic stress disorder. Depression and Anxiety, 9, 122130.

Smith, J. L., Johnstone, S. J., \& Barry, R. J. (2004). Inhibitory processing during the Go/NoGo task: an ERP analysis of children with attention-deficit/hyperactivity disorder. Clinical Neurophysiology, 115, 1320-1331.

Smith, N., Cacioppo, J., Larsen, J., \& Chartrand, T. (2003). May I have your attention, please: Electrocortical responses to positive and negative stimuli. Neuropsychologia, 41, 171-183.

Smith, N. K., Cacioppo, J. T., Larsen, J. T., \& Chartrand, T. L. (2003). May I have your attention, please: Electrocortical responses to positive and negative stimuli. Neuropsychologia, 41, 171-183.

Starcevic, V. (2008). Anxiety disorders no more? Australasian Psychiatry, 16(5), 317-321.

Summerfeldt, L. J., \& Endler, N. S. (1998). Examining the Evidence for Anxiety-Related Cognitive Biases in Obsessive-Compulsive Disorder. Journal of Anxiety Disorders, 
$12,579-598$.

Taake, I., Jaspers-Fayer, F., \& Liotti, M. (2009). Early frontal responses elicited by physical threat words in an emotional stroop task: modulation by anxiety sensitivity. Biological Psychology, 81, 48-57.

Tabachnick, B., Fidell, L., \& Osterlind, S. (2001). Using multivariate statistics.

Tata, P. R., Leibowitz, J. A., Prunty, M. J., Cameron, M., \& Pickering, A. D. (1996). Attentional bias in obsessional compulsive disorder. Behavior Research and Therapy, 34, 53-60.

Thibault, G., Felezeu, M., O'Connor, K. P., Todorov, C., Stip, E., \& Lavoie, M. E. (2008). Influence of comorbid obsessive-compulsive symptoms on brain event-related potentials in Gilles de la Tourette syndrome. Progress in Neuro-Psychopharmacology and Biological Psychiatry, 32, 803-815.

Thomas, S. J., Gonsalvez, C. J., \& Johnstone, S. J. (2009). Sequence effects in the Go/NoGo task: Inhibition and facilitation. International Journal of Psychophysiology, 74, 209219.

Thomas, S. J., Johnstone, S. J., \& Gonsalvez, C. J. (2007). Event-related potentials during an emotional Stroop task. International Journal of Psychophysiology, 63, 221-231.

Towey, J., Bruder, G., Hollander, E., Friedman, D., Erhan, H., Liebowitz, M., \& Sutton, S. (1990). Endogenous event-related potentials in obsessive-compulsive disorder. Biological Psychiatry, 28, 92-98.

Towey, J., Bruder, G., Tenke, C., Leite, P., DeCaria, C., Friedman, D., \& Hollander, E. (1993). Event-related potential and clinical correlates of neurodysfunction in obsessive-compulsive disorder. Psychiatry Research, 49, 167-181.

van den Heuvel, O. A., Veltman, D. J., Groenewegen, H. J., Dolan, R. J., Cath, D. C., Boellaard, R., van Dyck, R. (2004). Amygdala activity in obsessive-compulsive disorder with contamination fear: a study with oxygen- 15 water positron emission tomography. Psychiatry Research: Neuroimaging, 132, 225-237.

van den Heuvel, O. A., Veltman, D. J., Groenewegen, H. J., Witter, M. P., Merkelbach, J., Cath, D. C., van Dyck, R. (2005). Disorder-Specific Neuroanatomical Correlates of Attentional Bias in Obsessive-compulsive Disorder, Panic Disorder, and Hypochondriasis. Arch Gen Psychiatry, 62, 922-933.

van Hooff, J., Dietz, K., Sharma, D., \& Bowman, H. (2008). Neural correlates of intrusion of emotion words in a modified Stroop task. International journal of psychophysiology, 67, 23-34.

Vogel, E. K., \& Luck, S. J. (2000). The visual N 1 component as an index of a discrimination process. Psychophysiology, 37, 190-203.

Vuilleumier, P. (2005). How brains beware: neural mechanisms of emotional attention. Trends in Cognitive Sciences, 9, 585-594.

Weinstein, A. M. (1995). Visual ERPs evidence for enhanced processing of threatening information in anxious university students. Biological Psychiatry, 37, 847-858.

West, R. (2003). Neural correlates of cognitive control and conflict detection in the Stroop and digit-location tasks. Neuropsychologia, 41, 1122-1135.

Williams, J. M. G., Mathews, A., \& MacLeod, C. (1996). The Emotional Stroop Task and Psychopathology. Psychological Bulletin, 120, 3-24.

Williams, J. M. G., Watts, F. N., MacLeod, C., \& Mathews, A. (1997). Cognitive Psychology and Emotional Disorders. (2nd ed.). Chichester: Wiley.

Windmann, S., Sakhavat, Z., \& Kutas, M. (2002). Electrophysiological evidence reveals affective evaluation deficits early in stimulus processing in patients with panic disorder. Journal of abnormal psychology, 111, 357-369.

Zacharko, R. M., Koszycki, D., Mendella, P. D., \& Bradwejn, J. Behavioral, neurochemical, 
anatomical and electrophysiological correlates of panic disorder: multiple transmitter interaction and neuropeptide colocalization. Progress in Neurobiology, 47, 371-423.

Table 1.docx

Table 1. Participant characteristics and scores in psychometric questionnaires.

\begin{tabular}{|c|c|c|c|c|c|c|c|c|c|c|}
\hline $\begin{array}{l}\text { Variable } \\
\text { Val }\end{array}$ & & $\begin{array}{c}\mathrm{HC} \\
(n=20)\end{array}$ & & $\begin{array}{c}\text { PD } \\
(n=20)\end{array}$ & & $\begin{array}{c}\text { OCD } \\
(n=20)\end{array}$ & & $\begin{array}{l}\text { OCD } \\
\text { vs. HC }\end{array}$ & $\begin{array}{l}\text { OCD } \\
\text { vs. PD }\end{array}$ & $\begin{array}{l}\text { PD } \\
\text { vs. HC }\end{array}$ \\
\hline & & $\mathrm{N}$ & $\%$ & $\bar{N}$ & $\%$ & $\bar{N}$ & $\%$ & & & \\
\hline $\begin{array}{c}\text { Gender } \\
\text { Handedness }\end{array}$ & $\begin{array}{c}\text { Females } \\
\text { Right }\end{array}$ & $\begin{array}{l}12 \\
18\end{array}$ & $\begin{array}{l}60 \\
90\end{array}$ & $\begin{array}{l}15 \\
18\end{array}$ & $\begin{array}{l}75 \\
90\end{array}$ & $\begin{array}{l}11 \\
16\end{array}$ & $\begin{array}{l}55 \\
80\end{array}$ & $\begin{array}{l}N_{s} \\
\text { Ns }\end{array}$ & $\begin{array}{l}N_{s} \\
N_{s}\end{array}$ & $\begin{array}{l}\text { Ns } \\
\text { Ns }\end{array}$ \\
\hline Medication & $\begin{array}{c}\text { On psychotropic medication } \\
\text { SSRI } \\
\text { SNRI } \\
\text { RMA } \\
\text { TCA } \\
\text { Occasional benzodiazepine } \\
\end{array}$ & $\begin{array}{l}- \\
- \\
-\end{array}$ & $\begin{array}{l}\vdots \\
\vdots\end{array}$ & $\begin{array}{l}10 \\
3 \\
- \\
- \\
2 \\
5 \\
\end{array}$ & 50 & $\begin{array}{r}12 \\
9 \\
2 \\
1 \\
1 \\
1 \\
\end{array}$ & 60 & $* * *$ & Ns & $* * *$ \\
\hline \multirow[t]{2}{*}{ Comorbidities } & $\begin{array}{c}\text { Total comorbidities } \\
\text { Social phobia } \\
\text { Generalized anxiety } \\
\text { PTSD } \\
\text { Specific phobia } \\
\end{array}$ & & & $\begin{array}{l}10 \\
3 \\
3 \\
1 \\
3 \\
\end{array}$ & & $\begin{array}{l}10 \\
2 \\
4 \\
1 \\
3 \\
\end{array}$ & & & & \\
\hline & & M & SD & M & SD & M & SD & & & \\
\hline \multirow{3}{*}{$\begin{array}{c}\text { Age } \\
\text { Y-BOCS }\end{array}$} & & 30 & 11 & 36 & 10 & 37 & 10 & $N_{S}$ & $\mathrm{NS}_{\mathrm{s}}$ & $\overline{N_{s}}$ \\
\hline & $\begin{array}{l}\text { Obsessions } \\
\text { Compulsions }\end{array}$ & - & - & - & - & $\begin{array}{l}14 \\
12\end{array}$ & $\begin{array}{l}6 \\
6\end{array}$ & - & - & - \\
\hline & Total & - & - & - & - & 26 & 12 & - & - & - \\
\hline \multirow[t]{5}{*}{$\begin{array}{l}\text { Brief symptom } \\
\text { inventory (BSI) }\end{array}$} & $\begin{array}{l}\text { Depression subscale (DEP) } \\
\text { Phobic anxiety (PHOB) }\end{array}$ & $\begin{array}{r}0.56 \\
.25\end{array}$ & $\begin{array}{r}0.76 \\
.68\end{array}$ & $\begin{array}{l}1.2 \\
1.5\end{array}$ & $\begin{array}{l}0.95 \\
1.18\end{array}$ & $\begin{array}{l}1.49 \\
1.43\end{array}$ & $\begin{array}{r}1.07 \\
.95\end{array}$ & $\begin{array}{l}* * \\
* * *\end{array}$ & $\begin{array}{l}\text { Ns } \\
\text { Ns }\end{array}$ & $* *$ \\
\hline & Obsessive-Compulsive (OC) & 1.00 & .57 & 1.66 & 1.01 & 1.93 & 1.06 & $* *$ & Ns & * \\
\hline & Anxiety (ANX) & .56 & .54 & 1.68 & 1.05 & 2.14 & 1.02 & $* * *$ & Ns & **** \\
\hline & Global Severity Index (GSI) & .58 & .58 & 1.31 & .84 & 1.59 & .89 & $* * *$ & Ns & $* *$ \\
\hline & 'ositive Symptom Distress Index (PSDI) & 1.33 & .39 & 1.89 & .72 & 2.06 & .66 & $* * *$ & Ns & $* *$ \\
\hline \multirow{6}{*}{$\begin{array}{l}\text { Padua Inventory- } \\
\text { WWUR }\end{array}$} & Total score & 11 & 10.93 & 18.45 & 13.67 & 48.55 & 28.38 & $* * *$ & $* * *$ & Ns \\
\hline & Contamination/ washing subscale & 3.95 & 3.61 & 5.45 & 5.54 & 15.15 & 11.99 & $* * *$ & $* *$ & Ns \\
\hline & Dressing and grooming & .65 & 1.27 & 1.15 & 2.13 & 4.65 & 3.62 & $* * *$ & ** & Ns \\
\hline & Thoughts of harm & 1.55 & 2.31 & 3.50 & 3.22 & 7.65 & 6.34 & *** & * & $*$ \\
\hline & Impulses to ham & 1.40 & 2.78 & 3.30 & 4.95 & 4.60 & 5.75 & $*$ & Ns & Ns \\
\hline & Checking & 3.45 & 2.86 & 5.05 & 4.59 & 16.50 & 11.10 & $* * *$ & $* * *$ & Ns \\
\hline
\end{tabular}

Figure 1

Neutral

Color naming task $\quad$ Word classification task

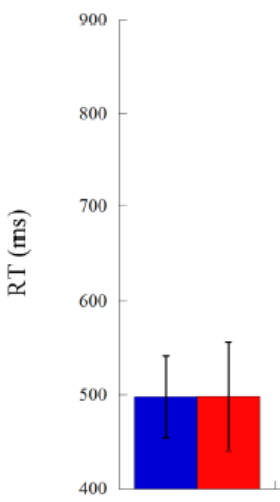

$\mathrm{HC}$

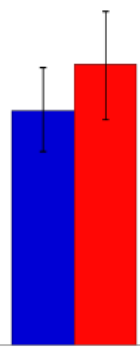

PD

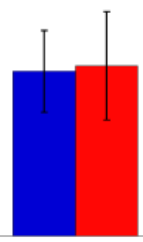

OCD

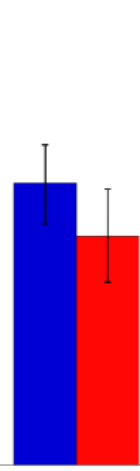

$\mathrm{HC}$

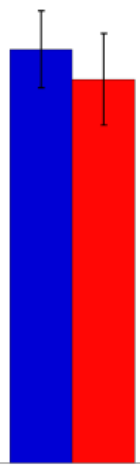

PD

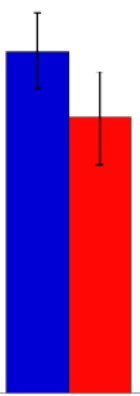

OCD

Figure 1. Mean RTs by group to threat and neutral stimuli in the color-naming and word classification tasks. Error bars reflect standard errors. 
Figure 2

Healthy control

color task

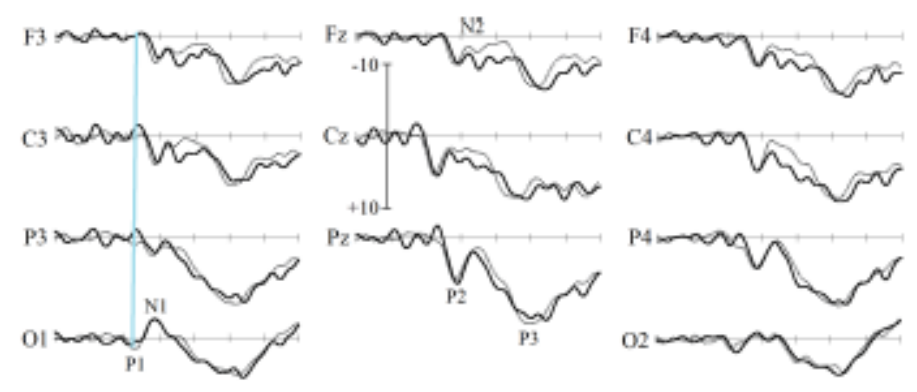

Panic disorder color task

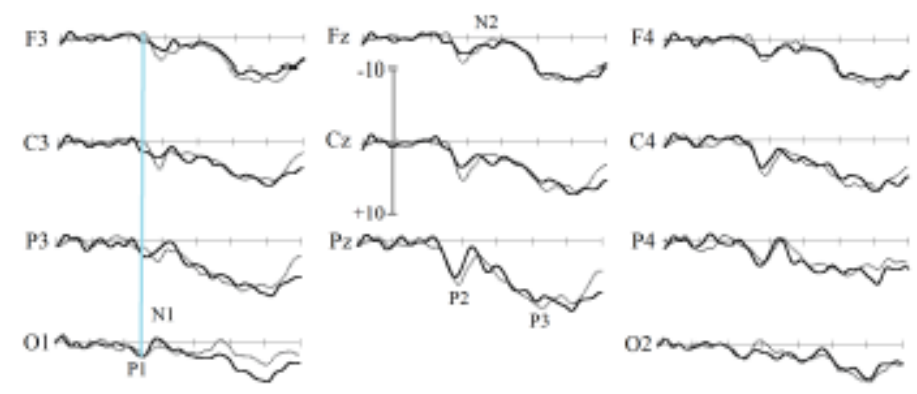

OCD

color task

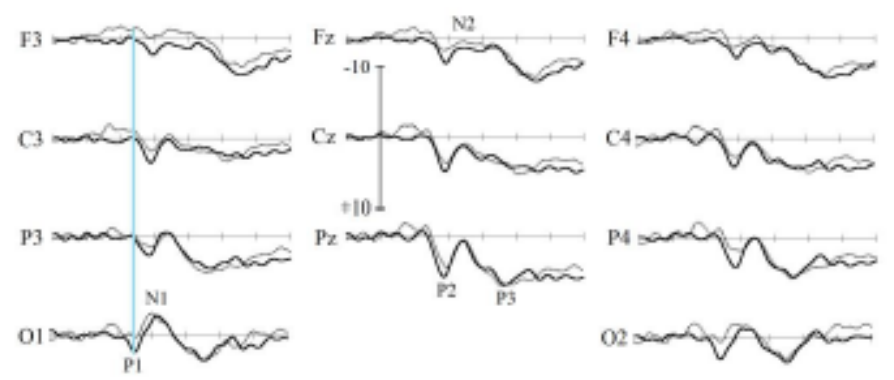




\section{Healthy control} word task

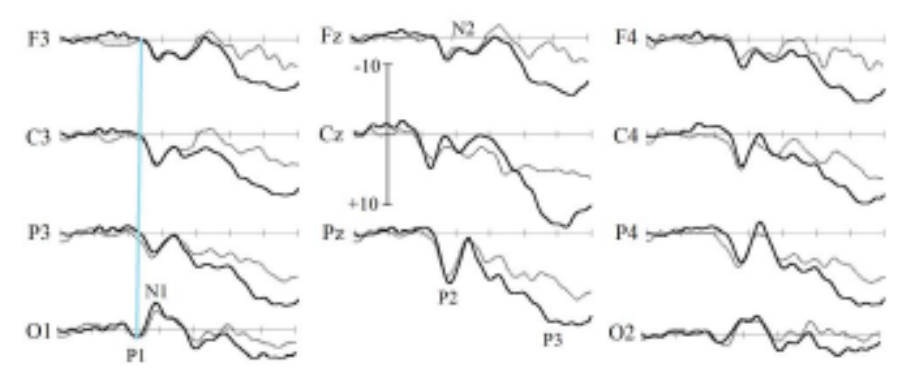

Panic disorder word task

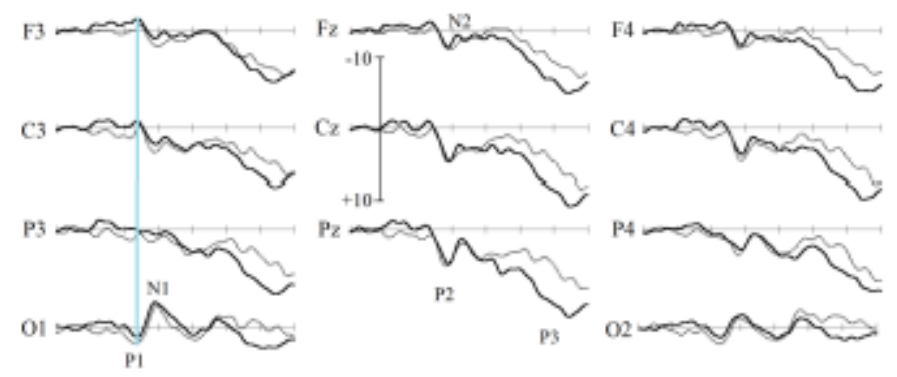

OCD

word task

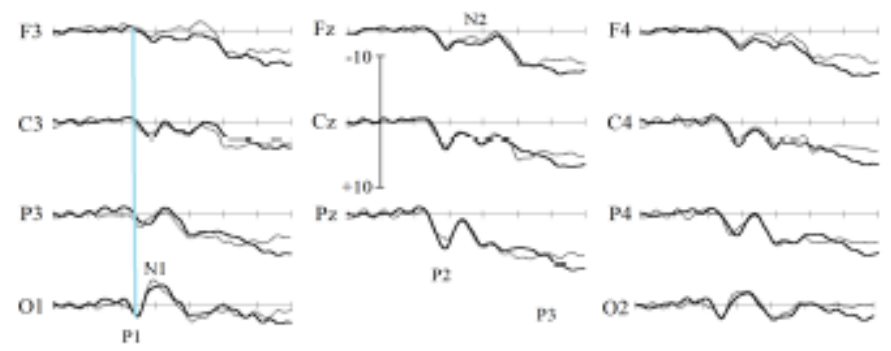

Neutral wurds Threat words 


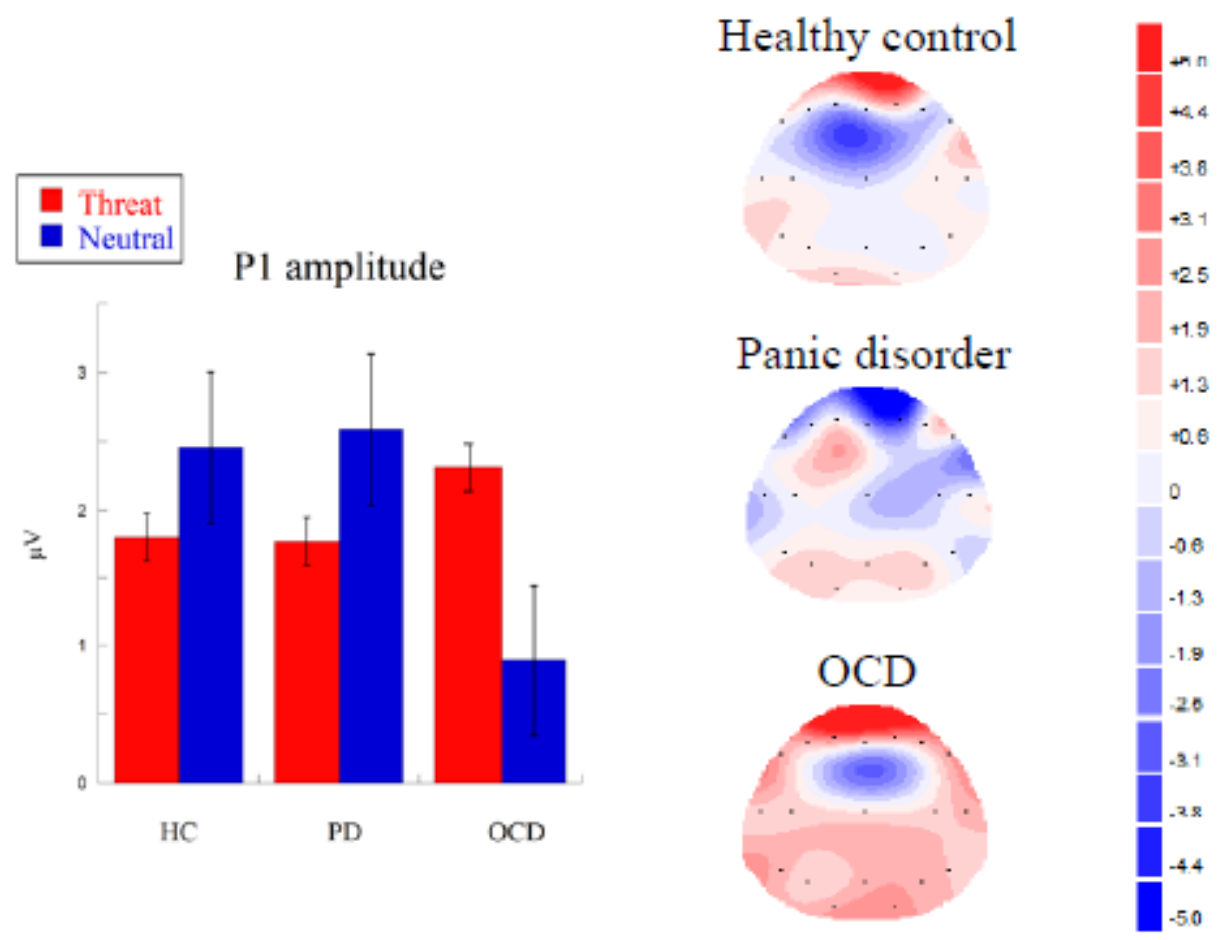

Figure 4. Pl amplitude to threat and neutral stimuli, by Group. Topographical maps indicate voltage difference for $\mathrm{Pl}$ amplitude for the threat minus neutral stimuli across tasks for each of the three groups (blue = negative difference; red $=$ positive difference) . 
Figure 5
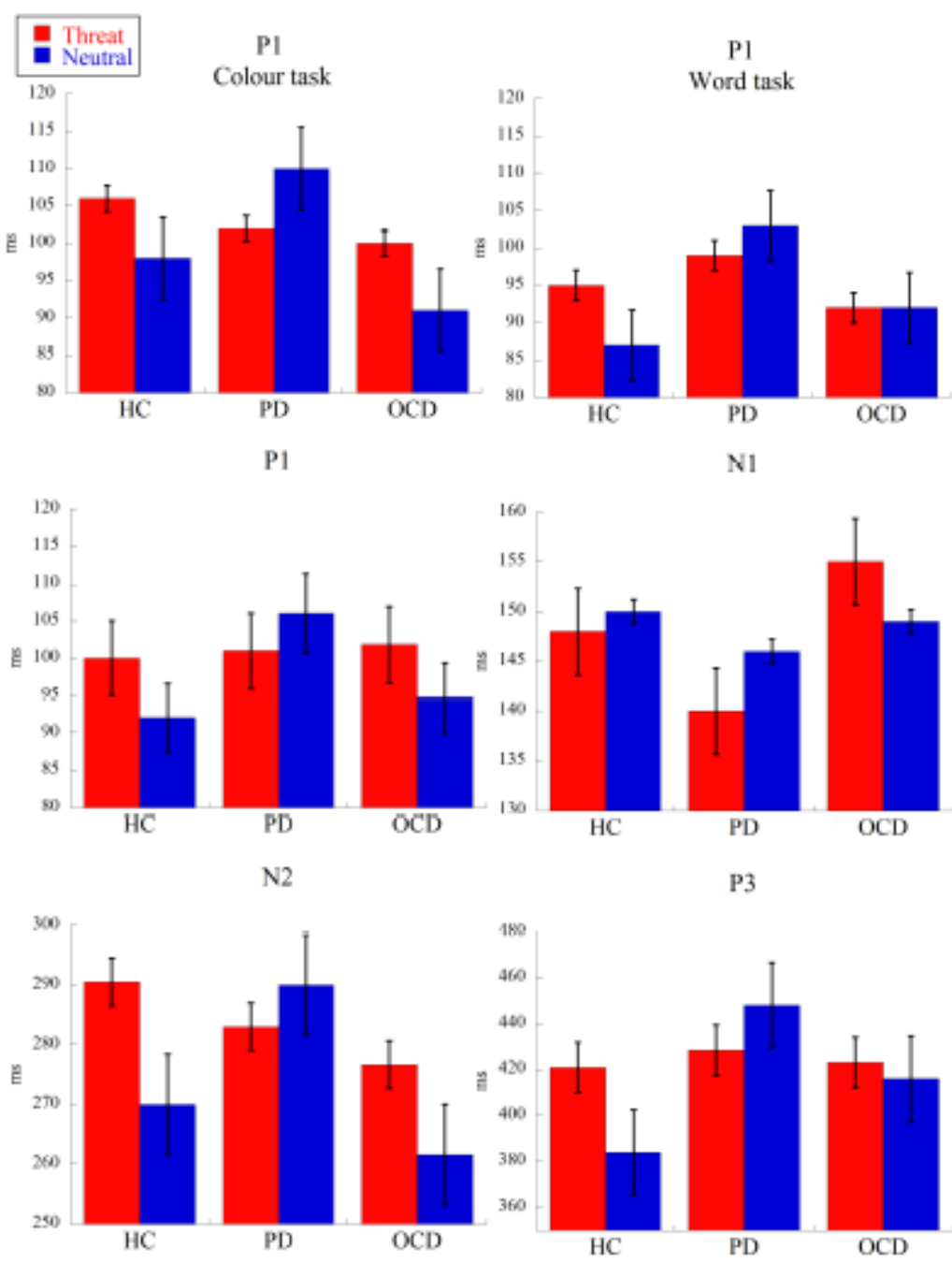

Figure 6.docx

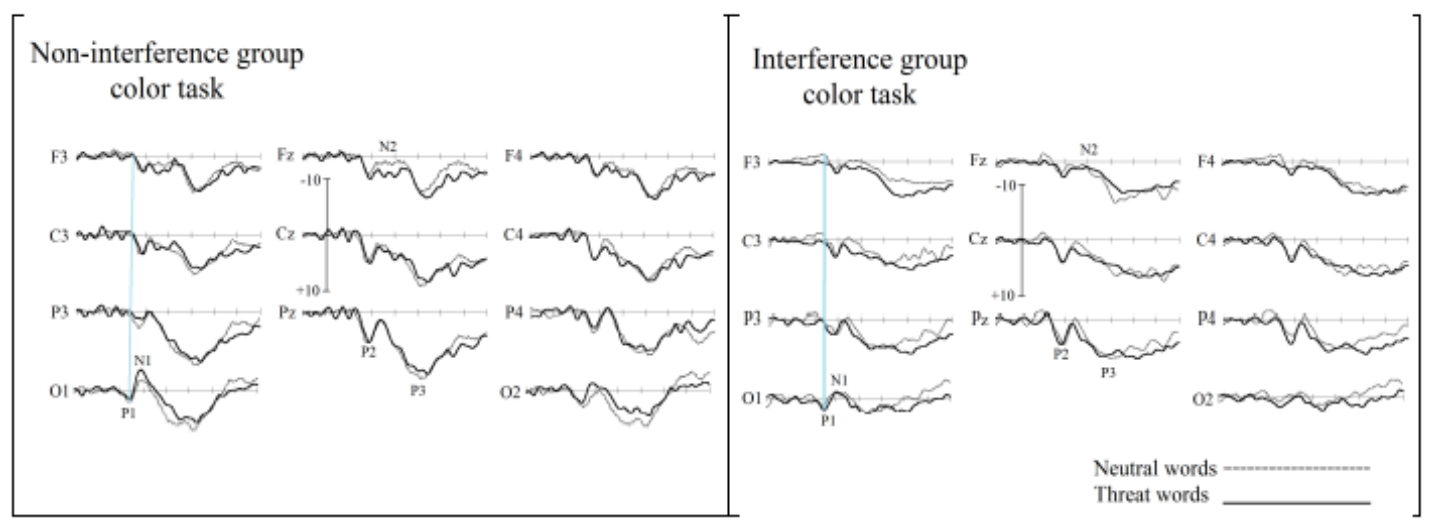


Threat
Neutral P1 amplitude

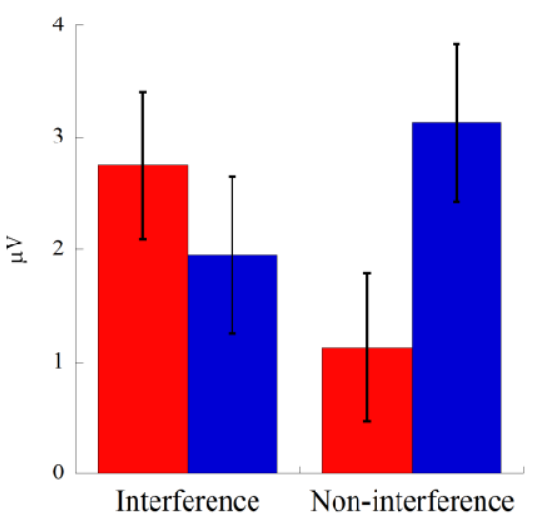

P3 amplitude

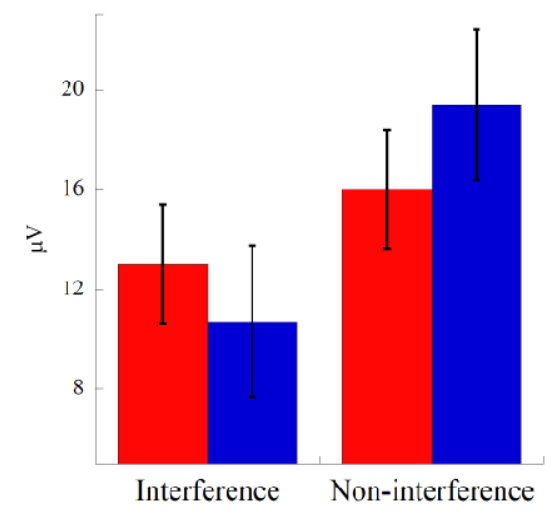



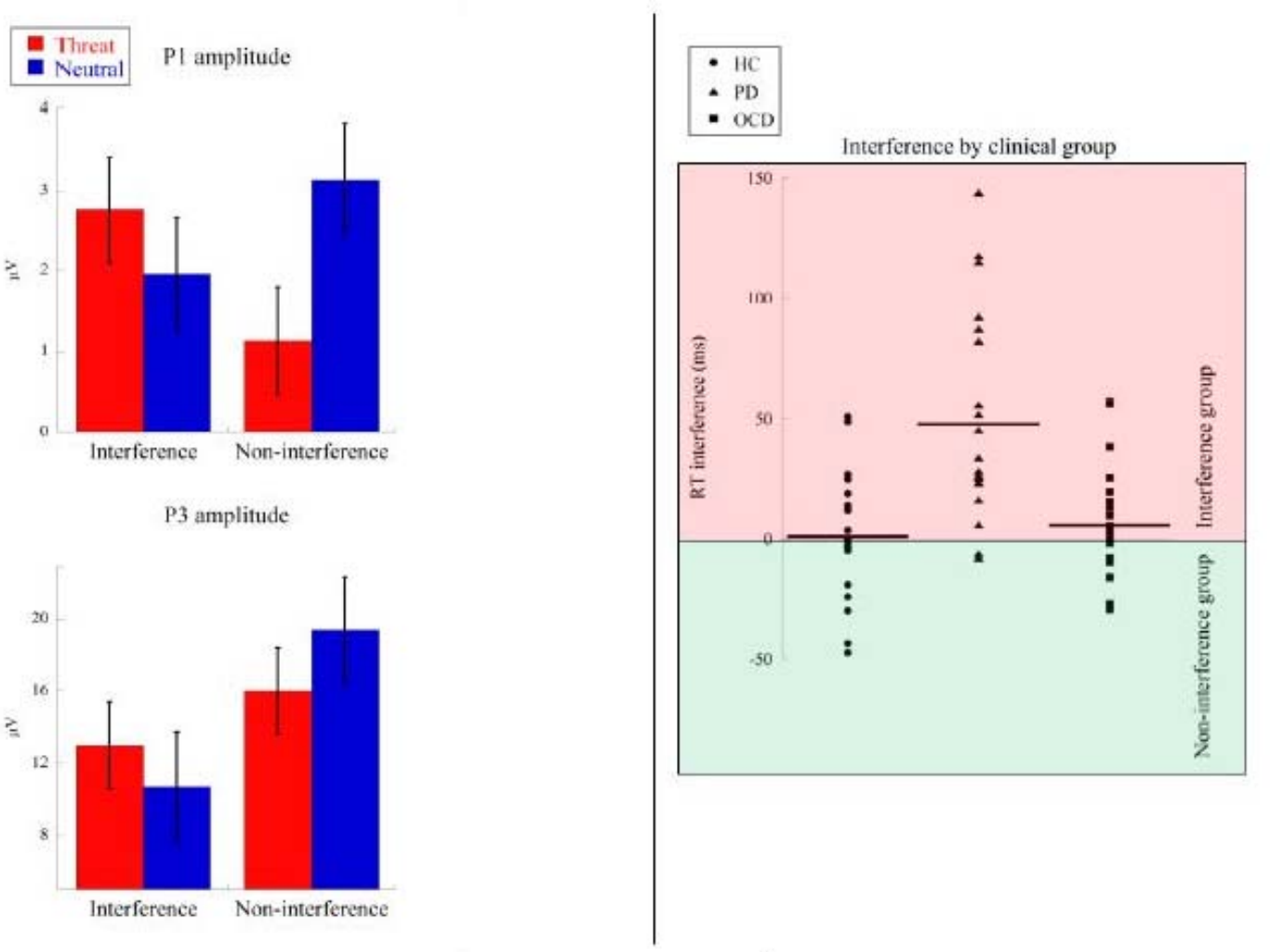